\title{
HoloGondel: in situ cloud observations on a cable car in the Swiss Alps using a holographic imager
}

\author{
Alexander Beck ${ }^{1}$, Jan Henneberger ${ }^{1}$, Sarah Schöpfer ${ }^{1}$, Jacob Fugal ${ }^{2}$, and Ulrike Lohmann ${ }^{1}$ \\ ${ }^{1}$ ETH Zurich, Institute for Atmospheric and Climate Science, Universitaetstrasse 16, 8092 Zurich, Switzerland \\ ${ }^{2}$ Johannes Gutenberg-Universitaet Mainz, Institute for Atmospheric Physics, J.-J.-Becherweg 21, 55099 Mainz, Germany \\ Correspondence to: Jan Henneberger (jan.henneberger@env.ethz.ch)
}

Received: 1 July 2016 - Discussion started: 1 August 2016

Revised: 21 December 2016 - Accepted: 9 January 2017 - Published: 6 February 2017

\begin{abstract}
In situ observations of cloud properties in complex alpine terrain where research aircraft cannot sample are commonly conducted at mountain-top research stations and limited to single-point measurements. The HoloGondel platform overcomes this limitation by using a cable car to obtain vertical profiles of the microphysical and meteorological cloud parameters. The main component of the HoloGondel platform is the HOLographic Imager for Microscopic Objects (HOLIMO 3G), which uses digital in-line holography to image cloud particles. Based on two-dimensional images the microphysical cloud parameters for the size range from small cloud particles to large precipitation particles are obtained for the liquid and ice phase. The low traveling velocity of a cable car on the order of $10 \mathrm{~m} \mathrm{~s}^{-1}$ allows measurements with high spatial resolution; however, at the same time it leads to an unstable air speed towards the HoloGondel platform. Holographic cloud imagers, which have a sample volume that is independent of the air speed, are therefore well suited for measurements on a cable car. Example measurements of the vertical profiles observed in a liquid cloud and a mixed-phase cloud at the Eggishorn in the Swiss Alps in the winters 2015 and 2016 are presented. The HoloGondel platform reliably observes cloud droplets larger than $6.5 \mu \mathrm{m}$, partitions between cloud droplets and ice crystals for a size larger than $25 \mu \mathrm{m}$ and obtains a statistically significantly size distribution for every $5 \mathrm{~m}$ in vertical ascent.
\end{abstract}

\section{Introduction}

The role of clouds remains a large source of uncertainty in climate and weather models (Flato et al., 2013) because our level of understanding of fundamental details of microphysical processes particular to mixed-phase clouds is low (Boucher et al., 2013). In situ measurements of the structure and the microphysical properties of clouds are important to gain a better knowledge of the radiative properties and the development of clouds (e.g., Sun and Shine, 1994; Morrison et al., 2012). Commonly these measurements are performed with a research aircraft (e.g., Verlinde et al., 2007; Vidaurre and Hallett, 2009; Heymsfield and Willis, 2014; Lawson et al., 2015), a helicopter (e.g., Siebert et al., 2006), a tethered balloon system (TBS) (e.g., Lawson et al., 2011; Sikand et al., 2013) or at mountain-top research stations (e.g., Rogers and Vali, 1987; Uchiyama et al., 2014; Geerts et al., 2015; Vochezer et al., 2016). This paper introduces a novel approach for measuring in situ properties of clouds on a cable car.

Airborne measurements have the ability to almost freely choose a flight path, which allows accurate control of time, in-cloud position and altitudes of the measurements. Multiple sampling of the same air mass in a Lagrangian manner is possible (Schumann et al., 2013), which allows us to explore the evolution of specific atmospheric phenomena or events for up to several hours. The possibility to equip an aircraft with a variety of in situ instrumentation (aerosol, chemistry, cloud microphysics) gives the opportunity to collect a comprehensive data set of clouds. However, with true air speeds on the order of $100 \mathrm{~m} \mathrm{~s}^{-1}$ the spatial resolution of in situ measurements on an airplane is limited, whereas in situ measure- 
ments on a helicopter with a true air speed on the order of $20 \mathrm{~m} \mathrm{~s}^{-1}$ achieve much better results (Siebert et al., 2006). In addition, the high traveling speed of an aircraft causes ice shattering on the tips of the instruments (Korolev et al., 2011, 2013). Harsh conditions during flight operation (e.g., turbulence, lightning strikes, rapid change of temperature, pressure and relative humidity during decent and accent) and the need for an instrument safety certification make the instrument development a time-consuming and expensive process. In addition, the high operational costs of an aircraft make airborne campaigns expensive and a successful performance depends on a detailed planning up to several months or years in advance by larger groups of people to support the logistics.

Tethered balloon systems can operate for an extended period of time $(>24 \mathrm{~h}$ ) and can measure the vertical profile of cloud properties from the surface to a height of $2 \mathrm{~km}$ and a wind speed below $10 \mathrm{~m} \mathrm{~s}^{-1}$ (Lawson et al., 2011). In comparison to airborne measurement, the main advantages of a tethered-balloon system are the higher spatial resolution, the reduced shattering of ice crystals and the lower operational costs. However, low payloads $(<15 \mathrm{~kg})$ and an operation only during low to moderate wind speeds $\left(<10 \mathrm{~m} \mathrm{~s}^{-1}\right)$ limit their operational capability.

Ground-based measurements, like tethered balloon systems, can measure for as long as several hours or even days at low operational cost (Henneberger et al., 2013). A spatial resolution comparable to a tethered balloon system can be achieved because wind speeds are lower than the traveling speed of aircraft. However, ground-based measurements are limited to single-point observations of the cloud and may be influenced by surface-based processes (Rogers and Vali, 1987; Geerts et al., 2015; Lloyd et al., 2015).

With the HoloGondel platform we introduce a novel approach to in situ cloud measurements. The HoloGondel platform is designed to be mounted on a cable car to measure vertical profiles of cloud properties. Previous studies have already made use of cable cars to obtain vertical profiles of temperature and relative humidity (Reiter, 1967; Reiter and Carnuth, 1975; Gultepe and Zhou, 2011; Joe et al., 2012), aerosol measurements (Reiter and Carnuth, 1975) or ozone soundings (Reiter, 1967; Baumann et al., 2001; Piringer et al., 2001). The HoloGondel platform is equipped with instruments to observe the meteorological parameters of temperature, relative humidity, wind speed and direction. In addition, the HoloGondel platform uses digital in-line holography to image cloud particles and observe microphysical properties of clouds.

Digital in-line holography has been previously used in a series of airborne (Conway et al., 1982; Fugal and Shaw, 2009; Beals et al., 2015) and ground-based field instruments (Thompson, 1964; Kozikowska et al., 1984; Borrmann and Jaenicke, 1993; Raupach et al., 2006; Henneberger et al., 2013). In comparison to other in situ cloud probes, holographic imagers have specific advantages and disadvantages (see Baumgardner et al., 2011). Holography allows one to measure over a wide range of particle sizes. Because images of the cloud particles are captured, no assumptions about the particle shape, orientation or refractive index are needed as are required for light scattering instrumentation (Lance et al., 2010). Holography also benefits from its well-defined sample volume, which is independent of particle size and air speed. This is of particular importance for the HoloGondel platform, because the air speed through the instrument depends on the varying wind speed and the travel velocity of the cable car. Finally it provides the spatial distribution of the particles in the sample volume on a millimeter scale (Beals et al., 2015). The principal disadvantage of holographic imaging systems is the high computational power required for data reconstruction and data analysis. However, with the progress in development of a suitable software package (HOLOSuite Fugal, 2017) and computer technologies, data reconstruction and analysis has become much faster.

Mounting the HoloGondel platform on a cable car enables acquisition of vertical profiles in complex alpine terrain. This is a major step forward compared to single point measurements conducted at mountain-top research stations. The HoloGondel platform can be easily mounted on cable cars at other locations. In addition, this approach offers the opportunity to obtain a vast set of vertical cloud profiles at low operational and organizational costs. The regular schedule of a cable car with up to 20 ascents and descents a day allows the observation of the temporal evolution of clouds during the day. The combined observations of vertical profiles of the phase-resolved particle size distribution and the spatial distribution of cloud particles with the meteorological parameters on the HoloGondel platform can enrich the already existing and comprehensive observations of cloud parameters with aircraft, tethered balloons and at mountaintop research stations and help to improve our understanding of clouds. For instance, ice crystal number concentrations (ICNC) that exceed the number of ice nuclei by up to 3 orders of magnitude were observed at the High Altitude Research Station Jungfraujoch (Henneberger et al., 2013). These observations suggest that a surface-based ice multiplication process like blowing snow (Rogers and Vali, 1987; Geerts et al., 2015) or hoar frost (Lloyd et al., 2015; Farrington et al., 2016) is active to produce the large ICNCs. The HoloGondel platform is able to correlate ICNC with cloud height and height above the surface and can help to further investigate the origin of high ICNC and possible multiplication mechanisms. Detailed information about the ice crystal habits from the pictures captured with the HoloGondel platform can be compared to ground-based (Shupe et al., 2008) and satellite (Zhang et al., 2010) remote sensing observations to further validate their retrievals. Information about the ice crystal habit is also important to simulate the fall velocity of ice crystals (Baumgardner et al., 2011), which affects the lifetime of a cloud.

With the HoloGondel platform boundary-layer liquid and mixed-phase clouds in mountain valleys can be observed. 
However, the findings of these measurements not only are applicable to boundary-layer clouds but also hold true for other cloud types if the findings are independent of the dynamics caused by the orography of the mountain valley. Therefore, measurements with the HoloGondel platform can contribute to a better understanding of fundamental details of microphysical processes in liquid and, in particular, mixed-phase clouds which are found in various cloud types.

This paper describes the HoloGondel platform with its instrumentation (Sect. 2) and introduces the newly developed HOLographic Imager for Microscopic Objects (HOLIMO 3G) in Sect. 3. In Sect. 4, two case studies of microphysical measurements with the HoloGondel on the cable car from Fiescheralp to the Eggishorn in the canton Valais in Switzerland are discussed. Section 5 summarizes first experiences with the HoloGondel platform and offers suggestions for improvements of the HoloGondel platform and further research opportunities.

\section{Description of the HoloGondel measurement platform}

The HoloGondel platform is designed to perform in situ cloud measurements on a cable car. Mounting a measurement platform on the roof of a cable car cabin requires the following design considerations:

First, the measurements platform must be lightweight, as an additional weight load due to a measurement platform reduces the admissible load weight of the cable car cabin. If this weight leads to a reduced number of admissible passengers, the operators of the cable car might charge a fee for the installation of the measurement platform. Therefore, the measurement platform needs to be carefully designed with respect to its weight.

Second, low power consumption is important. Typically, the lack of an external power supply on a cable car cabin requires the platform to be operated with a battery. A battery capacity that allows a continuous operation of the platform at least during the operating hours of the cable car is suggested. A high battery drain of the platform would require a larger battery capacity and result in a higher weight. This is in contradiction to the first requirement and requires a careful selection of power consuming components.

Third and finally, the different components of the measurement platform have to withstand the rough conditions on a cable car similar to but not as severe as other in situ cloud probes, e.g., as described in Spuler and Fugal (2011). These conditions include low temperatures $\left(0\right.$ to $\left.-20^{\circ} \mathrm{C}\right)$ and moist, precipitating and sometimes icing cloud environments, and they are potential dangers for the electronics of the instrument. In addition, ice chunks falling from the cable or supporting masts of the cable car can strike the instrument.

The main component of the HoloGondel platform (Fig. 1) is the HOLIMO $3 \mathrm{G}$ instrument, which measures a phase-

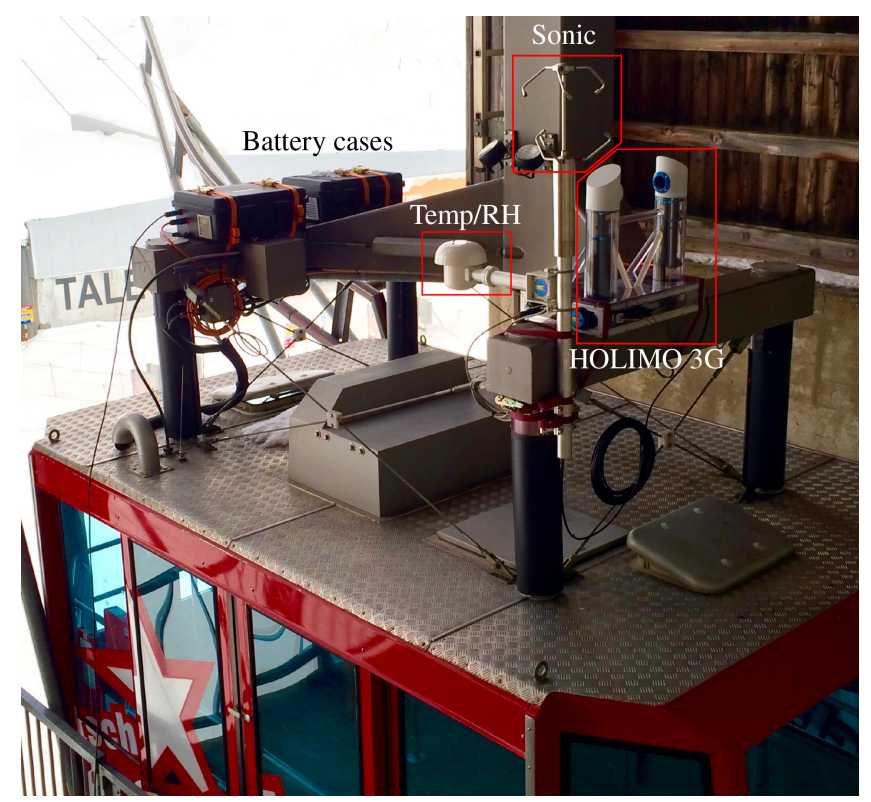

Figure 1. Experimental setup of the HoloGondel platform during the measurement campaign at the Eggishorn in the winter season 2016/2017. The picture was taken in the lower station of the cable car in Fiescheralp. The GPS sensor is not visible on this picture; it is mounted on the opposite side of the vertical mast.

resolved size distribution, concentrations and water content (see Sect. 3.1). The HOLIMO 3G instrument was designed to meet the requirements of the HoloGondel platform, i.e., low in power consumption and weight (see Sect. 3.2). It consists of a single watertight box, which also houses the control and data-acquisition computer of the HoloGondel platform. The data are temporarily stored on two 1 TB solid-state drives (SSDs). Because of the large amount of data acquired (up to 1 TB per day) a local server storage (Synology NAS) is placed in the control room at the base station of the cable car. A wireless network adapter is installed to transfer the data from the instruments SSDs to the local server storage during the night. In addition, the HOLIMO $3 \mathrm{G}$ instrument is equipped with a mobile router that allows remote access of the instrument via the mobile data network.

The HoloGondel platform is also equipped with a 3-D sonic anemometer (THIES), a heated temperature and humidity sensor (HygroMet4, Rotronic; $\pm 2-3 \%$ RH for subzero temperatures, $4 \mathrm{~Hz}$ ) in a ventilated weather housing (RS24T, Rotronic) and a GPS sensor (BU-353S4, GlobalSat). A summary of the instruments mounted on the HoloGondel platform and their observables is given in Table 1. The entire setup is powered by two battery packs with a capacity of $1.5 \mathrm{kWh}$ each, which is enough for continuous operation of the platform of at least $20 \mathrm{~h}$. The batteries can be fully recharged in $10 \mathrm{~h}$.

The wind measurements of the 3-D sonic anemometer have to be corrected for the movement of the cable car rel- 
Table 1. Summary of the instruments mounted on the HoloGondel platform and their observables.

\begin{tabular}{ll}
\hline Instrument & Observable \\
\hline HOLIMO 3G & Size distribution \\
& $\begin{array}{l}\text { Particle concentration } \\
\text { Water content } \\
\end{array}$ \\
& Spatial distribution \\
& Ice crystal shape \\
& Wind velocity and direction \\
3-D sonic anemometer, & Turbulence \\
Theiss & Virtual temperature \\
HygroMet4, Rotronic & Temperature \\
& Relative humidity \\
GPS, GlobalSat & Location \\
& Velocity above ground \\
\hline
\end{tabular}

ative to the actual wind velocity. For this correction the direction and speed of the cable car relative to the surface were calculated from GPS data and subtracted from the wind measurements. RH measurements on the HoloGondel platform are used only to indicate in-cloud conditions, because measurements of RH in clouds are challenging. To protect the sensor from dew it is heated to a temperature of $8 \mathrm{~K}$ above the ambient temperature and the measurement is corrected for the temperature difference between the heated sensor and the ambient air. Because the accuracy of the humidity sensor is $2-3 \% \mathrm{RH}$ at sub-zero temperatures, we consider measurements above $95 \% \mathrm{RH}$ as in-cloud conditions.

The total weight of the HoloGondel platform is about $60 \mathrm{~kg}$. The HOLIMO $3 \mathrm{G}$ instrument is the heaviest component with a weight of $18 \mathrm{~kg}$ followed by the two battery packs at $16 \mathrm{~kg}$ each. The additional meteorological instrumentation weighs $10 \mathrm{~kg}$.

The HoloGondel platform is designed for modular operation and only HOLIMO $3 \mathrm{G}$ is indispensable as it houses the control and data-acquisition computer for the entire platform. Additional instruments, e.g., aerosol instruments or other cloud probes, can independently be added to the setup limited only by the weight and power restrictions. Also the battery packages can be used together or singly. Therefore, the HoloGondel platform can be adapted to the scientific question as well as the weight requirements of different cable cars.

\section{HOLographic Imager for Microscopic Objects}

The HOLIMO 3G instrument is the third generation of holographic imagers (HOIMO I, Amsler et al., 2009; HOLIMO II, Henneberger et al., 2013) developed over the last 9 years in the Atmospheric Physics group at the ETH Zurich and is designed for use on a cable car. HOLIMO 3G has an open path configuration allowing ambient air to stream freely between the towers and observation of spatial particle distributions on a millimeter scale. In contrast, its predecessor HOLIMO II had an inlet aspirated with a calibrated flow powered by a pump, which meant compensating for nonisokinetic sampling and loss of the spatial distribution of particles in the sample. In addition, the open path configuration leads to a more compact design because heavy equipment like a pump to ensure a calibrated air flow is not necessary and helped to reduce the weight (see Sect. 2).

\subsection{Working principle of HOLIMO $3 G$}

The setup of a simple digital in-line holographic system is shown in Fig. 2. The main components are a laser as a coherent light source and a digital camera to record the image or hologram. In general, a lens is added behind the laser to collimate the light and a lens system is required in front of the digital camera to achieve the desired resolution (Spuler and Fugal, 2011). To acquire single particle information with digital in-line holography, two steps are necessary (Fugal et al., 2009). First, a liquid droplet or ice crystal in the sample volume scatters the light and an interference pattern between the scattered and reference waves is recorded. This interference pattern is the hologram. In the second step, single particle information is extracted from the recorded hologram using the open source HoloSuite software package (Fugal, 2017). In this step the hologram is reconstructed along the optical axis and the in-focus position of the particle is determined ( $\mathrm{Fu}$ gal et al., 2009). The result is a set of 2-D images, which are sorted into the three categories of artifacts, liquid droplets and ice crystals using supervised machine learning based on a set of parameters (e.g., aspect ratio, minimal/maximal phase or amplitude value of a pixel, amplitude gradient in the 2-D image) and the particle diameter is computed. To reduce the noise level in a hologram background division is performed as described in Fugal et al. (2009). This method reduces noise that is constant from hologram to hologram, such as particles stuck on the optical components or a nonuniform laser beam profile. Cloud droplets larger than $6.2 \mu \mathrm{m}$ can be observed with HOLIMO $3 \mathrm{G}$, which is approximately 2 times the effective pixel size of $3.1 \mu \mathrm{m}$. To separate cloud droplets from ice crystals based on the shape of the particle, a picture of at least eight pixels is needed. Following the considerations in Henneberger (2013) the threshold to differentiate between cloud droplets and ice crystals was set to $25 \mu \mathrm{m}$, which corresponds to 8 times the effective pixel size of the camera sensor. However, some ice crystals may be still misclassified as cloud droplets depending on their shape and orientation.

\subsection{Instrument description}

Due to the open path configuration of the newly designed HOLIMO 3G instrument, it was possible to reduce the weight by more than a factor of 2 compared to its predecessor 


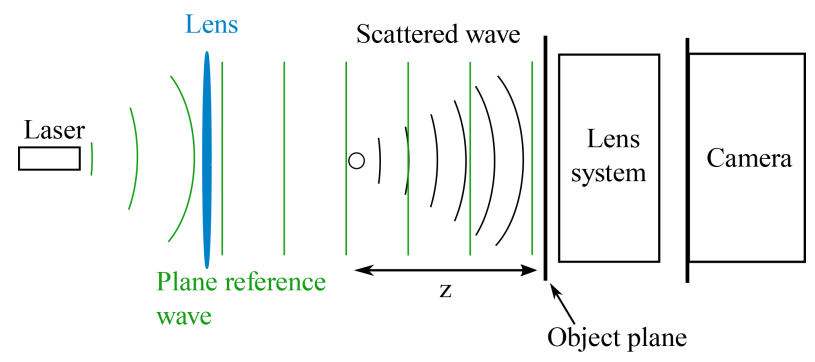

Figure 2. Schematic of the working principle of digital in-line holography. The reference wave emitted by a laser is collimated using a convex lens. The plane reference wave is scattered by a particle and the generated scattered wave interferes with the reference wave to form an interference pattern. To improve the resolution of the system, the interference pattern in the object plane is magnified with a lens system before projection on the camera sensor.

HOLIMO II. This was possible because several components (e.g., blower, flow meter, heating, rotor) of the HOLIMO 2 setup, necessary for the inlet-based design, are not required for the HOLIMO $3 \mathrm{G}$ instrument. In addition, the components of the new instrument were carefully selected with respect to their weight (e.g., single-board computer, polycarbonate housing).

The new design of the HOLIMO $3 \mathrm{G}$ instrument is distinguished by its two towers on top of the hermeticallysealed box (Fig. 3), which houses a single-board computer (ADLE3800PC, ADL Europe, Germany), two 1 TB SSDs (Samsung 840 EVO), a mobile router (RBMTXI, M2M, Germany) and a laser. The single-board computer has a compact design and low power consumption, and the SSDs withstand possible vibrations on top of the cable car. The passively Q-switched Nd:YAG laser with a wavelength of $532 \mathrm{~nm}$ (FDSS532Q4, CryLas, Germany) emits pulses with a width of $1.4 \mathrm{~ns}$ and a pulse energy of $42 \mu \mathrm{J}$. The laser beam is coupled into a fiber to transport the beam to one of the towers, which also cleans the laser profile because only the lowest transverse electromagnetic mode is transmitted. Before the fiber, the laser beam is attenuated by approximately $70 \%$ using a neutral density filter to protect the fiber from damages. After the fiber the laser beam is collimated to a diameter of $40 \mathrm{~mm}$ with a lens mounted in the tower. Windows are installed in the white tips of the towers to allow the laser beam to exit and re-enter the instrument. The windows are made of sapphire because of its high heat conductivity $\left(\approx 23 \mathrm{~W} \mathrm{~m} \mathrm{~K}^{-1}\right.$ ) compared to the standard N-BK7 glass and are heated to prevent freezing and to evaporate cloud particles stuck to the window. The distance between the sapphire windows is $24 \mathrm{~cm}$. As evaporated cloud droplets leave behind aerosol particles and other aerosol particles impact on the windows, the intensity of the holograms is decreased and the noise is increased, making regular cleaning of the windows necessary.
At the bottom of the second tower a $30 \mathrm{MP}$ camera (HR29050, SVS-Vistek, Germany) with a pixel size of $5.5 \mu \mathrm{m}$ is installed to capture holograms. The camera and the laser are software triggered and synchronized with a maximal frequency of six frames and pulses per second. On top of the camera a bi-telecentric lens system (Sill Optics S5LPJ3618/M58) with a magnification of 1.8 and a numerical aperture of 0.11 is mounted. The described setup achieves a resolution of $6.2 \mu \mathrm{m}$ within a distance of approx. $75 \mathrm{~mm}$ from the sapphire window of the tower with the camera and lens system (see Sect. 3.3). To prevent an influence due to flow distortion if the wind arrives obliquely to HoloGondel the first centimeter of the sample volume outside the window of the camera side is excluded from the analysis. With a cross-sectional area of $20 \mathrm{~mm} \times 13.4 \mathrm{~mm}$ and an effective depth of $65 \mathrm{~mm}$ the corresponding sample volume is $17 \mathrm{~cm}^{3}$. The entire sample volume between the towers is $60 \mathrm{~cm}^{3}$ and has a reduced resolution of $20 \mu \mathrm{m}$. While the smaller sample volume with a high resolution enables observation of both the smaller liquid droplets and larger ice crystals, the large sample volume can be used to obtain better statistics of the fewer ice crystals. With a maximal frame rate of $6 \mathrm{fps}$ this results in a sample volume rate of $100 \mathrm{~cm}^{3} \mathrm{~s}^{-1}$ for the small sample volume and $360 \mathrm{~cm}^{3} \mathrm{~s}^{-1}$ for the entire detection volume between the two towers. Data presented in this work are only extracted from the small sample volume.

For the smaller sample volume of $17 \mathrm{~cm}^{3}$ and a droplet concentration on the order of $100 \mathrm{~cm}^{-3}$, the Poisson counting error is less than $3 \%$. However, for the smaller ice crystals concentration on the order of $100 \mathrm{~L}^{-1}$ the Poisson counting error yields $73 \%$ for the small sample volume of a single hologram. Therefore, at least 50 holograms were grouped together to decrease the Poisson counting error of ice crystals to a value below 11 and below $1 \%$ for the cloud droplets.

\subsection{Resolution measurements}

As described in Henneberger et al. (2013) the resolution of a holographic system is limited by three constraints. One limitation is imposed by the pixel size of the camera $\left(D_{\text {pixel }}\right)$ and the magnification of the lens system $(M)$ :

$D_{\text {res,pixel }}=\frac{2 D_{\text {pixel }}}{M}=2 \times D_{\text {pixel,eff }}$,

where $D_{\text {pixel,eff }}$ is the effective pixel size on the image side of the system. The remaining two resolution limits can be calculated using half the Rayleigh criterion:

$D_{\text {res }}=\frac{1.22 \lambda}{\mathrm{NA}}$,

with the wavelength $\lambda$ and the numerical aperture NA, which is the sine of half of the acceptance angle of the optical system. The numerical aperture of the lens system $\left(\mathrm{NA}_{\text {lens }}\right)$ is a property of the lens design resulting in a resolution limit of

$D_{\text {res,lens }}=\frac{1.22 \lambda}{\mathrm{NA}_{\text {lens }}}$. 

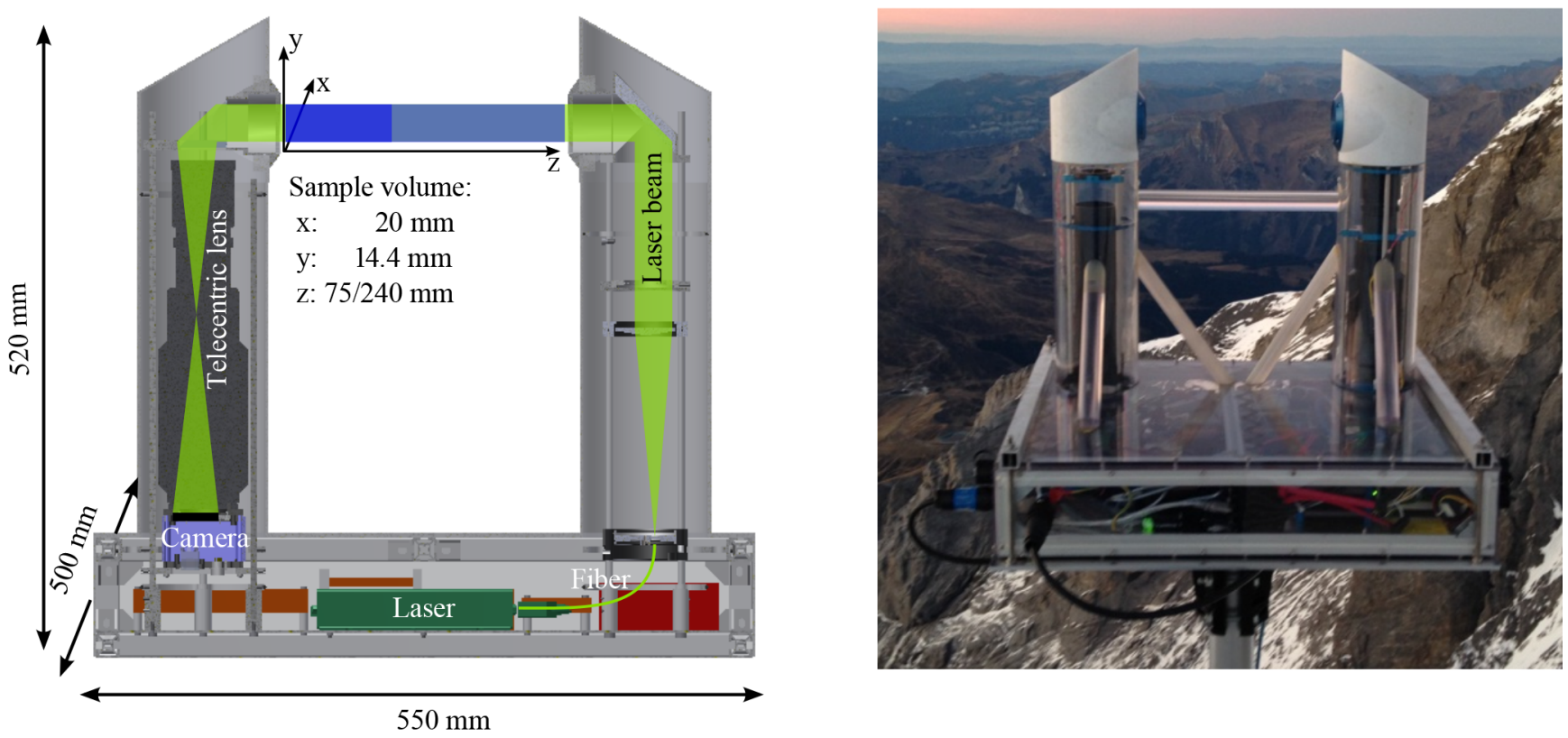

Figure 3. Technical drawing (left) and a picture (right) of the HOLIMO $3 \mathrm{G}$ instrument with its main components. The ambient air streams freely between the two towers and the detection volume is the field of view of the instrument between the two towers. The dark blue box indicates the sample volume with the highest resolution $(6.2 \mu \mathrm{m})$ and a depth of $75 \mathrm{~mm}$. The dark and light blue boxes indicate the entire sample volume between the towers with a depth of $240 \mathrm{~mm}$. Because the resolution decreases for distances larger $75 \mathrm{~mm}$ the minimal resolution in the large sample volume is $20 \mu \mathrm{m}$ (Fig. 4).

The numerical aperture of the optical setup of a holographic system can be calculated from its effective aperture $D_{\text {eff }}$ and the reconstruction distance $z_{\text {rec }}$ :

$\mathrm{NA}_{\text {lens }} \approx \frac{D_{\text {eff }}}{2 z_{\text {rec }}}$.

The resulting resolution limit $D_{\text {res,rec }}$ is therefore a linear function of the reconstruction distance $z$ :

$D_{\text {res,rec }}=\frac{2.44 \lambda}{D_{\text {eff }}} \times z_{\text {rec }}$.

The strongest constraint of the above-mentioned resolution limits determines the optical resolution of the instrument. To ensure a high resolution over a large reconstruction distance, the optical parameters of the components have to be carefully matched. For $z<8 \mathrm{~cm}$, the pixel size limits the resolution of the HOLIMO $3 \mathrm{G}$ instrument with a theoretical resolution limit of $D_{\text {res,pix }}=6.2 \mu \mathrm{m}$, which corresponds to 2 times the effective pixel size of $3.1 \mu \mathrm{m}$. For larger reconstruction distances $D_{\text {res,rec dominates (Fig. 4). }}$

The theoretical considerations of the resolution limits of the instrument were verified with laboratory measurement using an US Air Force resolution target (1951 USAF) as it was done by Spuler and Fugal (2011). The target is a glass plate with a series of patterns of three horizontal and three vertical bars where the distance between the bars is twice their width. The optical resolution limit of the evaluated sys-

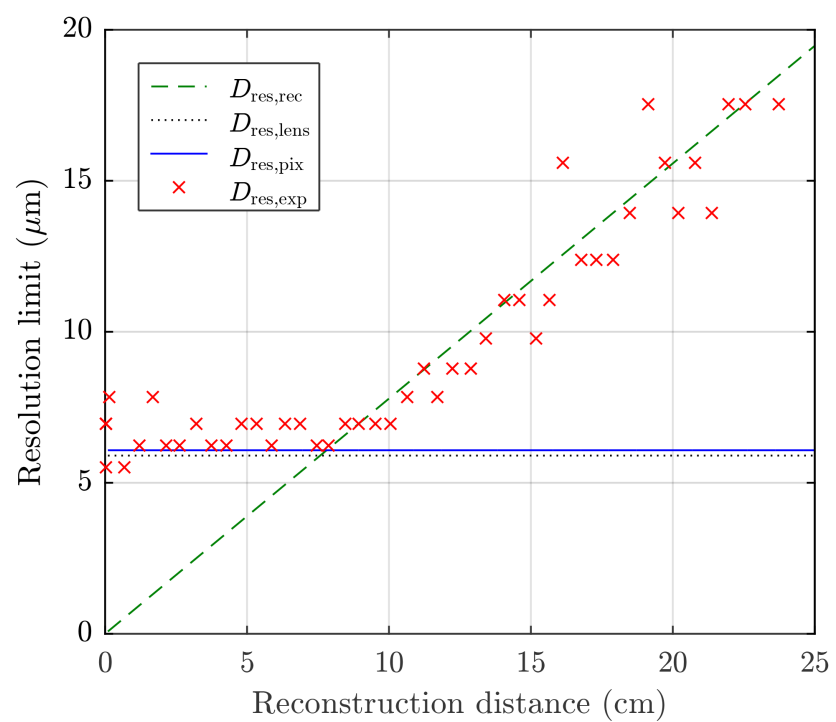

Figure 4. Resolution measurements of the HOLIMO $3 \mathrm{G}$ instrument versus reconstruction distance ( $z$ in Fig. 3). The three lines indicate theoretical calculations for the resolution limit due to the pixel size $\left(D_{\text {res,pix }}\right)$, the optical limitation of the lens system $\left(D_{\text {res,lens }}\right)$ and the optical setup of the instrument ( $\left.D_{\text {res,rec }}\right)$. The red crosses represent the results of the resolution measurements with a US Air Force resolution target (1951 USAF). 


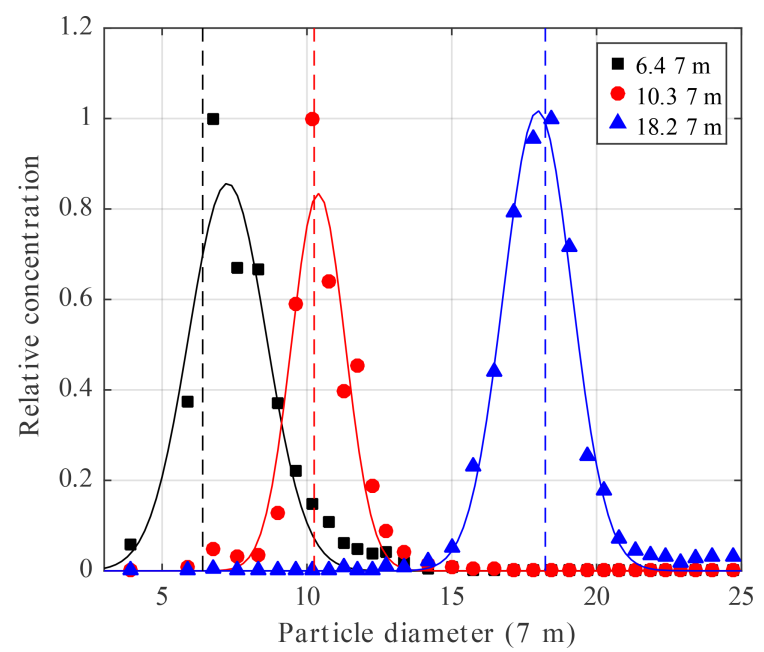

Figure 5. Result of the calibration measurement for HOLIMO $3 \mathrm{G}$ with monodisperse spheres with diameters of $6.4,10.3$ and $18.2 \mu \mathrm{m}$. The symbols represent the normalized concentrations measured by HOLIMO 3G. A Gaussian distribution is fitted (solid line) and compared to the nominal size (dashed line).

tem is defined by the distance between the bars of the smallest pattern of which both the horizontal and vertical lines can still be resolved. During the measurements the target was placed at various positions inside of the sample volume. Within a reconstruction distance of $1<z<8 \mathrm{~cm}$ the measurements are close to the theoretical resolution limit of $6.2 \mu \mathrm{m}$ (Fig. 4). Also the observed increase of the resolution limit due to $D_{\text {res,rec }}$ for reconstruction distances larger than $8 \mathrm{~cm}$ is in good agreement with the theoretical calculations. Small deviations of the observations from the theoretical calculations for $z<1 \mathrm{~cm}$ are caused by disturbances from the virtual image and the regular pattern that the bars of the resolution target represent to the hologram.

\subsection{Calibration of HOLIMO 3G}

The sizing algorithm of the HOLOSuite software package was calibrated for the HOLIMO $3 \mathrm{G}$ instrument following Henneberger et al. (2013). Cross-linked poly methyl methacrylate (PMMA) spheres (colloquial acrylic glass) of diameters $6.4,10.25$ and $18.23 \mu \mathrm{m}$ and a density of $1180 \mathrm{~kg} \mathrm{~m}^{-3}$ were suspended in air using a Fluidized Bed Aerosol Generator (FBG model 3400a, TSI, Minnesota, USA). Their size was measured with the HOLIMO 3G instrument and an Aerodynamic Particle Sizer (APS model 3321, TSI, Minnesota, USA). The results for HOLIMO 3G are normalized to the maxima of the observed size distribution and Gaussian distributions fitted to the three sample sizes (Fig. 5). These results and the results of the APS are compared to the nominal diameter measured by the manufacturer (Microbeads, Norway) with a COULTER Multisizer 3 (Table 2).
Table 2. Comparison of the results of the calibration measurements of HOLIMO $3 \mathrm{G}$ with the results of an Aerodynamic Particle Sizer (APS model 3321, TSI, Minnesota, USA) and the data provided by the manufacturer from a COULTER Multisizer 3. The uncertainties of the HOLIMO $3 \mathrm{G}$ and APS data were calculated from a Gaussian fit to the normalized size distribution.

\begin{tabular}{llll}
\hline & \multicolumn{3}{c}{ Particle diameter $(\mu \mathrm{m})$} \\
\hline Multisizer & $6.40 \pm 0.11$ & $10.25 \pm 0.19$ & $18.23 \pm 0.24$ \\
HOLIMO 3G & $7.32 \pm 1.95$ & $10.48 \pm 1.34$ & $18.10 \pm 1.67$ \\
APS & $6.56 \pm 0.29$ & $10.12 \pm 0.67$ & $17.93 \pm 1.35$ \\
\hline
\end{tabular}

The results of both the APS and the HOLIMO 3G instrument agree with the nominal diameter within their uncertainties. Although a trend towards an overestimation of the spheres with a smaller diameter is visible, a size correction similar to the one introduced by Henneberger et al. (2013) is not applied because all the results agree within in the square root of a pixel size with the nominal diameter. This is in agreement with a study by Lu et al. (2008), which shows a similar accuracy of the algorithm for larger particle sizes.

\section{Field measurements}

\subsection{Description of the measurement site}

The field measurements were conducted on the cable car between the Fiescheralp $\left(46^{\circ} 24^{\prime} \mathrm{N} 8^{\circ} 06^{\prime} \mathrm{E}\right)$ and the Eggishorn $\left(46^{\circ} 25^{\prime} \mathrm{N} 8^{\circ} 05^{\prime} \mathrm{E}\right)$ in the canton Valais in Switzerland (see Fig. 6, right). Over a horizontal distance of $1716 \mathrm{~m}$ it covers a vertical elevation of $654 \mathrm{~m}$, with a maximum altitude of $2871 \mathrm{ma}$ a.s.l. The height of the cable car above the surface varies between 20 and $110 \mathrm{~m}$ along its path between the Eggishorn and the Fiescherlap (see Fig. 6, left). An overview of the technical parameters of the cable car is given in Table 3 .

The setup of the HoloGondel platform during the campaign in winter 2016 is shown in Fig. 1. The instruments (HOLIMO 3G, Sonic, Temp/RH) are mounted on the downhill facing side of the cable car approx. $1.20 \mathrm{~m}$ above the cabin roof. In winter 2015, the instrumentation was the same except temperature, humidity and wind sensors were not present, just the HOLIMO 3G and the GPS.

We present two case studies one each from the campaigns in winter 2015 and 2016. The first case study represents a situation with a liquid cloud (hereafter referred to as the "liquid case") that was observed on 23 February 2016. The second case study represents a situation with a mixed-phase cloud (hereafter referred to as the "mixed-phase case") on 21 March 2015.

During the liquid case, the temperature at the Eggishorn varied between -8 and $-5^{\circ} \mathrm{C}$. On this day a cold front was moving from the north towards the Alps, resulting in a pre- 

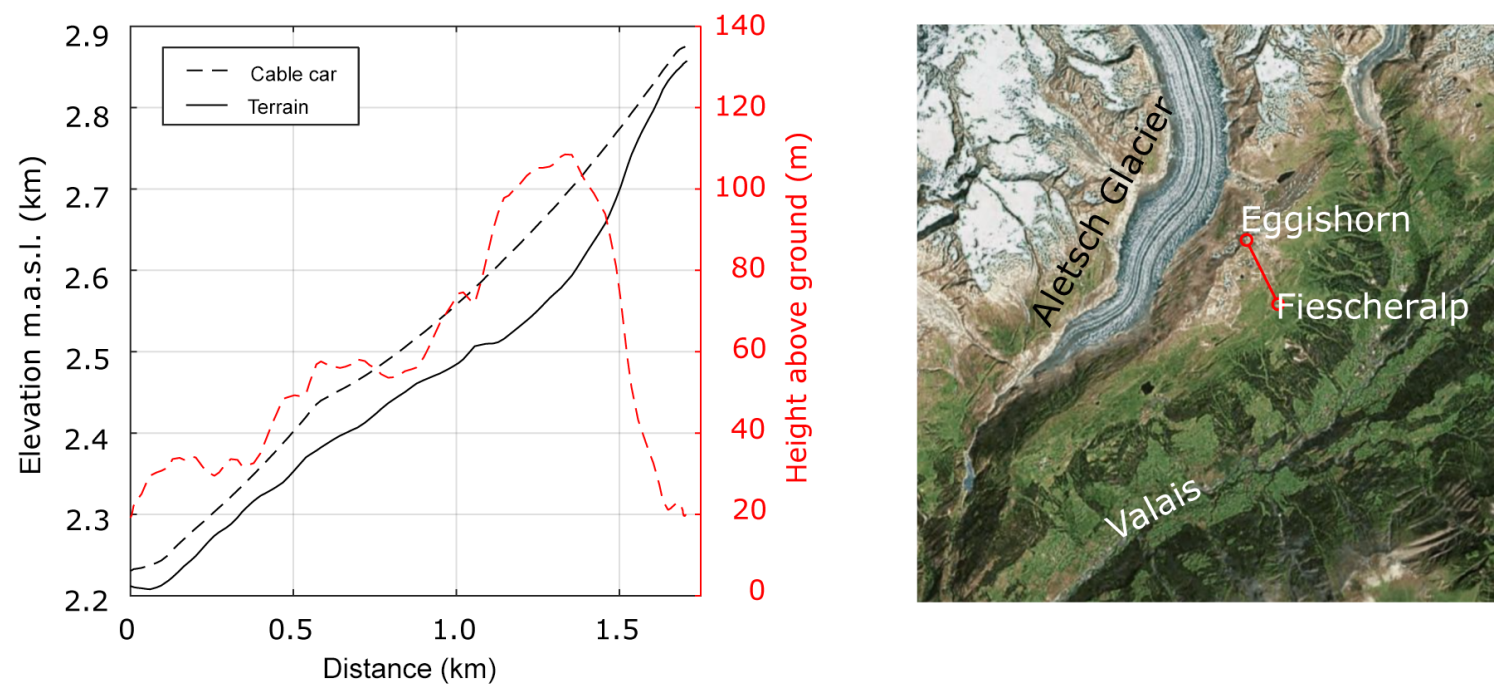

Figure 6. Left: profile of the terrain (solid black line) and a ride of the cable car (dashed black line) together with the height of the cable car above the surface (solid red line). Right: map of the measurement site.

Table 3. Overview of the technical parameters of the cable car Fiescheralp-Eggishorn. See Fig. 6 for further details.

\begin{tabular}{lr}
\hline Altitude bottom station (Fiescheralp) & $2217 \mathrm{ma.s.1}$ \\
Altitude top station (Eggishorn) & $2871 \mathrm{ma.s.1}$ \\
Vertical distance & $654 \mathrm{~m}$ \\
Horizontal distance & $1716 \mathrm{~m}$ \\
Average slope & $38 \%$ \\
Maximal slope & $57 \%$ \\
Average speed & $10 \mathrm{~m} \mathrm{~s}^{-1}$ \\
Average travel time & $200 \mathrm{~s}$ \\
\hline
\end{tabular}

dominantly westerly wind direction at the Eggishorn with wind speeds between 2 and $8 \mathrm{~m} \mathrm{~s}^{-1}$. A patchy cloud cover in the morning and a uniform cloud cover in the afternoon was observed from satellite pictures, but no precipitation was detected by the nearby radar from high clouds and no snowfall was observed on the ground at the MeteoSwiss station at the Eggishorn. During the mixed-phase case, the temperature varied between -7 and $-4{ }^{\circ} \mathrm{C}$ and a low pressure system over northeast Germany led to a southwesterly flow with wind speeds up to $5 \mathrm{~ms}^{-1}$ at the Eggishorn. On this day a cirrus cloud layer was observed from satellite pictures above the Eggishorn, but no precipitation.

For an approximately 3-minute ascent or descent with the cable car, the HoloGondel platform captures a maximum of $\sim 1200$ holograms. For the liquid case, an average of $\sim 240$ holograms (4 L sampled volume) were analyzed for each run of the cable car for a total of 10 runs. Additionally, for one run 1200 holograms, 20 L of air was analyzed. For the mixed-phase case 400 holograms (6.8 L sampled volume) were processed per run, for a total of 4 runs. When examin- ing vertical profiles, at least 10 holograms $(0.17 \mathrm{~L}$ sampled volume) are processed and presented as a group per level to obtain better counting statistics. This results in a vertical resolution of $5 \mathrm{~m}$ (Fig. 9). For a uniform presentation of the data of the liquid and mixed-phase cases the data are presented in $75 \mathrm{~m}$ intervals, which correspond to 30 holograms for the liquid case and 50 holograms for the mixed-phase case. An exception is the presentation of the height-resolved size distribution for the liquid case in Fig. 8. For a clearer presentation these data are averaged over four height intervals of $150 \mathrm{~m}$.

\subsection{Liquid case}

For the analysis, the data of 23 February 2016 are split into two groups representing different cloud behaviors.

During the morning the height profiles of the meteorological parameters (Fig. 7) imply relatively steady conditions with a wind from west-southwest independent of altitude. The median wind speed over the reported height intervals decreased from $6 \mathrm{~m} \mathrm{~s}^{-1}$ at the Fiescheralp to $2 \mathrm{~m} \mathrm{~s}^{-1}$ at the Eggishorn. The reported relative humidity persistently exceeded $96 \%$ independent of the altitude and time. Considering the accuracy of the relative humidity sensor, this was assumed to be a condition saturated with respect to liquid water. The median temperature over the $75 \mathrm{~m}$ altitude intervals ranged between -6.2 and $-3.5^{\circ} \mathrm{C}$.

The cloud droplet number concentration (CDNC) varied with altitude and over time (Fig. 7) in the morning of 23 February 2016. During the first run in the morning, almost no cloud droplets were observed with the HOLIMO $3 \mathrm{G}$ instrument $\left(<5 \mathrm{~cm}^{-3}\right)$. Later in the morning, a CDNC up to $250 \mathrm{~cm}^{-3}$ was present at altitudes below $2500 \mathrm{~m}$ while a 
23 February 2016
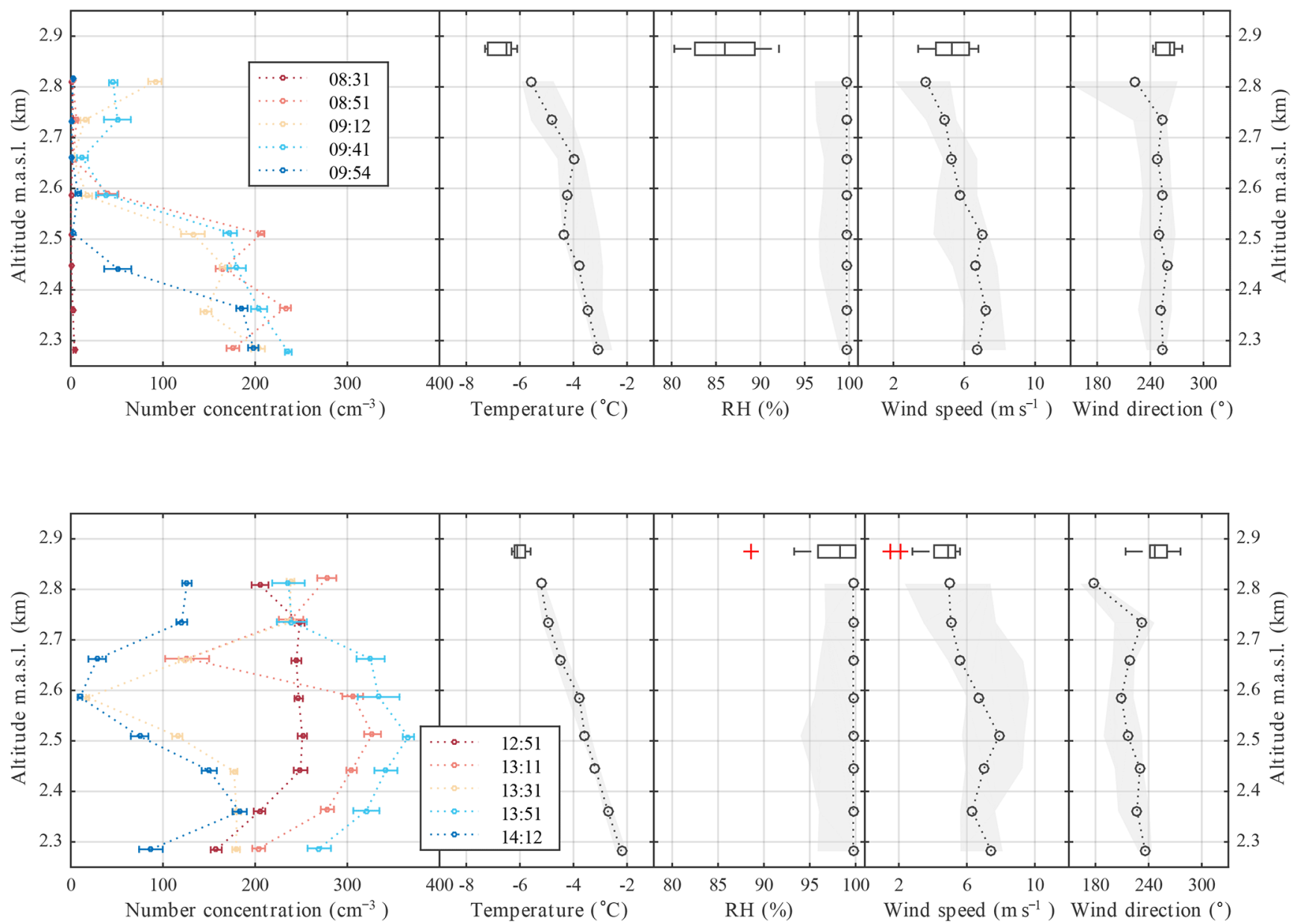

Figure 7. Height profiles of the liquid case measured with the HoloGondel platform during the morning (top) and the afternoon (bottom) of 23 February 2016. The data are averaged over an altitude interval of $75 \mathrm{~m}$. The number concentration of cloud droplets (left panel) shows individual runs of the cable car. The error bars represent the standard error of the mean. For the meteorological parameters (four right panels) the median (circle), the minimum and the maximum (shaded area) values of the vertical intervals are shown. The box plots indicate the data of the MeteoSwiss station at the Eggishorn about $50 \mathrm{~m}$ above the cable car station for comparison. For each box, the central line marks the median value of the measurement and the left and right edges of the box represent 25th and the 75th percentiles respectively. The whiskers extend to minimum and maximum of the data; outliers are marked as red pluses.

smaller CDNC of $100 \mathrm{~cm}^{-3}$ or less were observed close to the Eggishorn. The height-resolved size distribution of the run at 08:51 UTC (Fig. 8) shows a decrease of mean droplet diameter from 11.8 to $10.6 \mu \mathrm{m}$ with decreasing altitude.

The observations can be explained by fog that was formed lower in the valley, rose in the early morning and persisted with its top at an altitude of $2500 \mathrm{~m}$. This temporal evolution was also observed by the webcam pictures of the Eggishorn and the Fiescheralp. After 09:41 UTC the cloud top began to sink again. This can be explained by the evaporation of cloud droplets at the cloud top due to the absorption of solar radiation. The observed CDNC of 150 to $250 \mathrm{~cm}^{-3}$ and droplet size of $11 \mu \mathrm{m}$ is in the range for fog or stratus clouds (Lohmann et al., 2016).
During the early afternoon the observed meteorological conditions were similar to the morning (Fig. 7). The temperature was nearly the same, wind speed was a little higher (up to $10 \mathrm{~m} \mathrm{~s}^{-1}$ ) and the wind direction near the top station turned towards the south. Only the relative humidity showed a higher variability with values as low as $94 \%$ at an altitude of $2500 \mathrm{~m}$. This observation is reflected by the measurements of the CDNC, which vary highly over time at an altitude of $2600 \mathrm{~m}$. At 12:51, 13:11 and 13:51 UTC CDNCs between 250 and $380 \mathrm{~cm}^{-3}$ are observed. The concentration is close to $0 \mathrm{~cm}^{-3}$ for the runs at 13:31 and 14:12 UTC at an altitude of $2600 \mathrm{~m}$, which indicates a pocket of clear air (see also Fig. 9). 
23 February 2016

$08: 51$

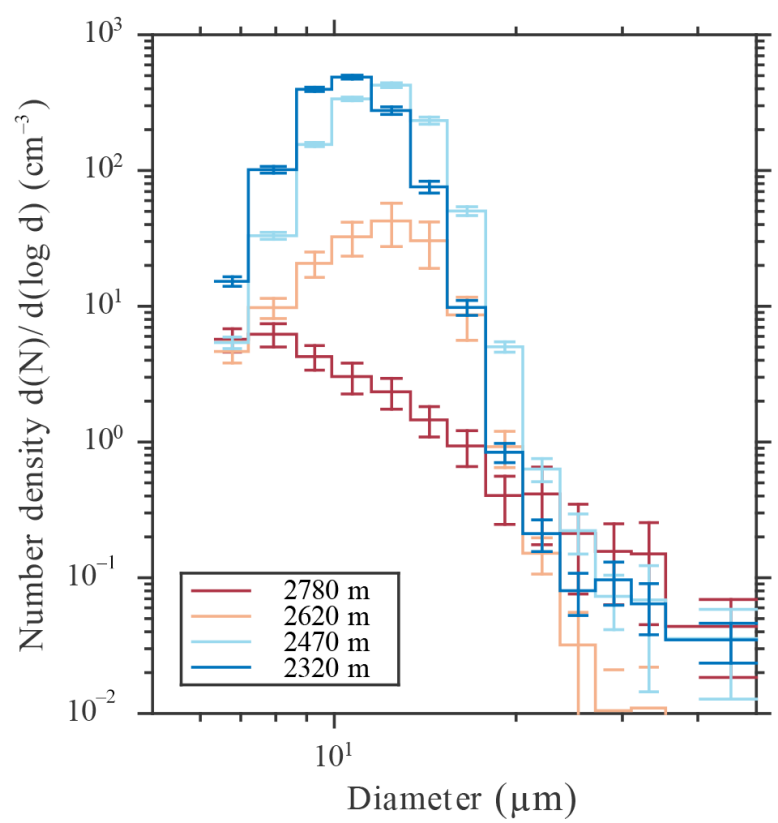

$13: 31$

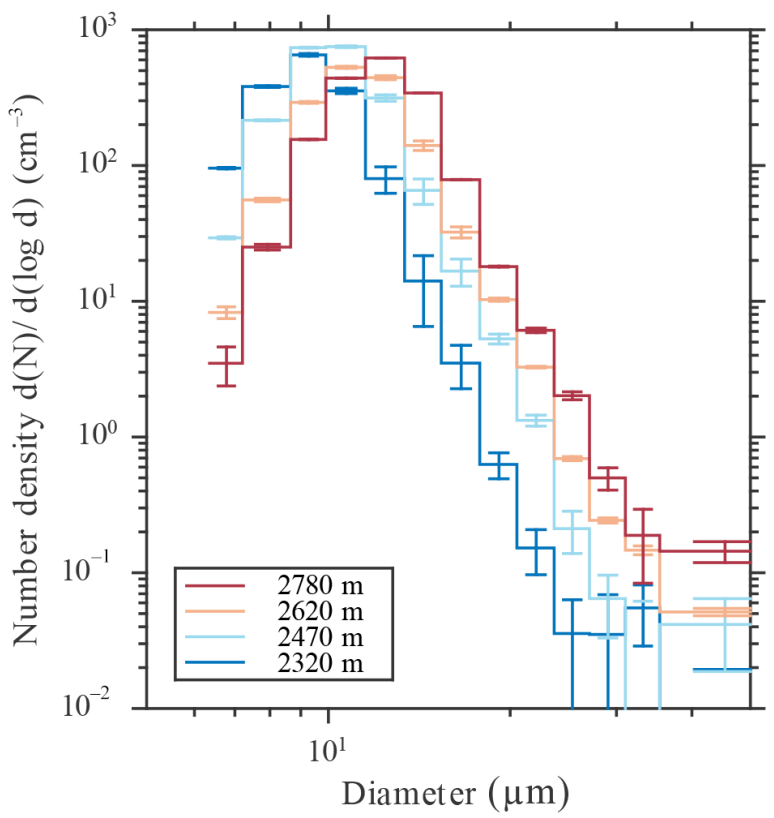

Figure 8. Height-resolved cloud droplet size distribution during the 08:51 UTC run in the morning (left) and the 13:31 UTC run in the afternoon. The data were averaged over an altitude interval of $150 \mathrm{~m}$. The error bars represent the standard error of the mean.

\section{3:31 on 23 February 2016}
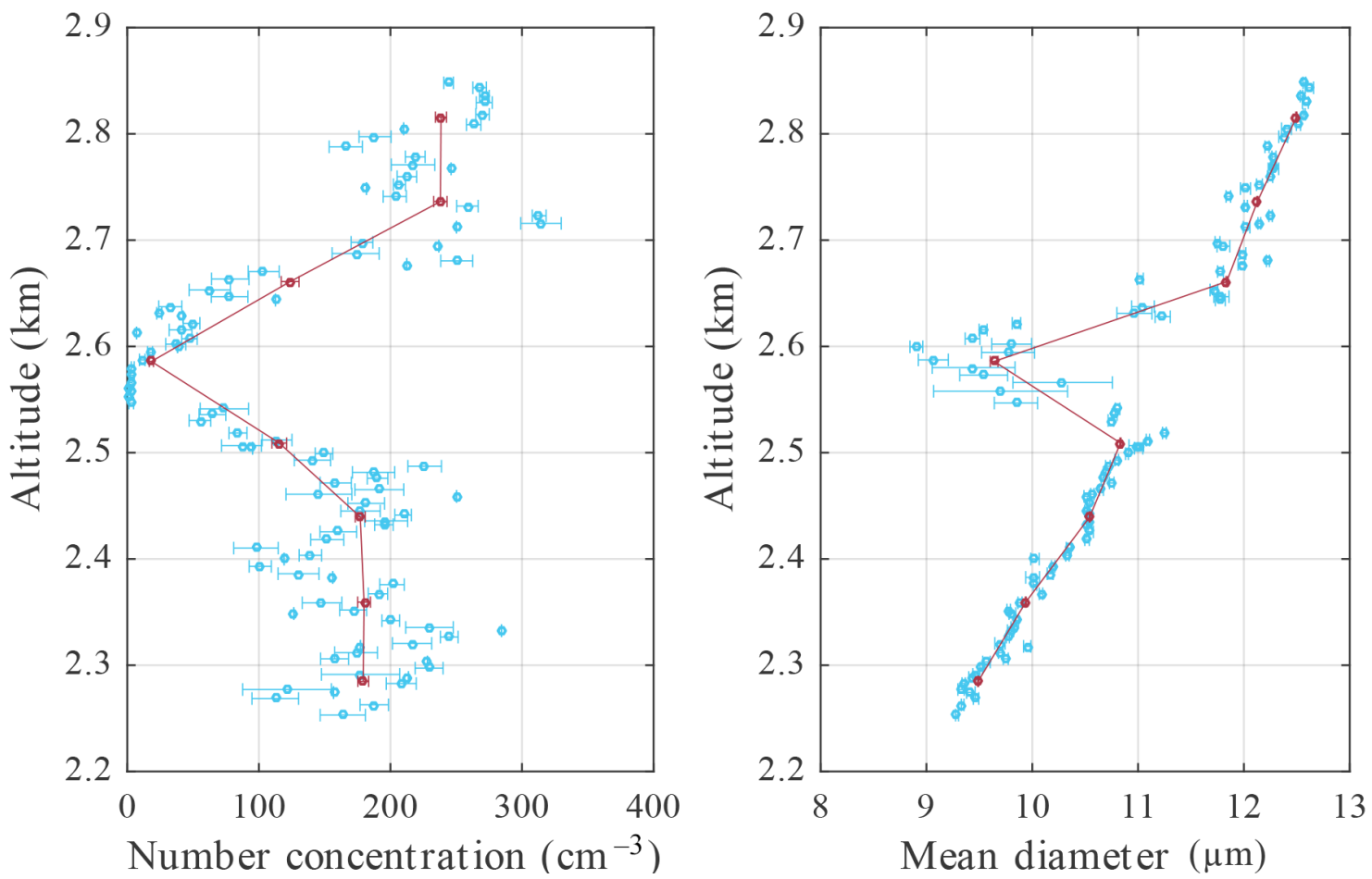

Figure 9. Comparison of two vertical profiles for the cloud droplet number concentration (left) and mean cloud droplet diameter (right) for the run at 13:31 UTC on February 2015. The vertical profiles in blue show the maximal vertical resolution of the HoloGondel platform of $5 \mathrm{~m}$. The vertical profiles in red are averaged over an vertical interval of $75 \mathrm{~m}$. The error bars represent the standard error of the mean. 
The CDNC was typically around $200 \mathrm{~cm}^{-3}$ during the afternoon. Remarkable is the observation of a CDNC close to $400 \mathrm{~cm}^{-3}$ at an altitude of $2500 \mathrm{~m}$ at 13:51 UTC, which is still within the range of typical values for stratus clouds (Lohmann et al., 2016). Although the background in a hologram increases at such high number concentrations, manual inspection of the particle images has shown that the algorithm is still capable of reliably distinguishing between artifacts and cloud droplets (see also Sect. 5.2).

Although a uniform cloud cover was observed from satellite pictures above the Eggishorn in the afternoon, the observation shows a high variability of the $\mathrm{CDNC}$ at an altitude of $2600 \mathrm{~m}$. Over four runs of the cable car the CDNC alternates between $350 \mathrm{~cm}^{-3}$ and less than $50 \mathrm{~cm}^{-3}$. This illustrates the capability of the HoloGondel platform to observe the temporal evolution of a cloud with a resolution of $20 \mathrm{~min}$ and shows the patchiness of the cloud cover during the day. With a mean horizontal wind speed of $5 \mathrm{~m} \mathrm{~s}^{-1}, 20$ min corresponds to a variation in the vertical cloud structure over a horizontal distance of $\lesssim 6 \mathrm{~km}$. The height-resolved size distribution (Fig. 8) shows an increase of the mean cloud droplet diameter from 10 to $15 \mu \mathrm{m}$ with increasing altitude. This is expected in a cloud dominated by condensational growth (Lohmann et al., 2016) and in agreement with lidar observations of shallow tropical cumuli, which show an increase of the effective radius above cloud base (McFarlane and Grabowski, 2007).

In Fig. 9 the vertical profiles of CDNC and mean diameter at the maximum vertical resolution of the HoloGondel platform of $5 \mathrm{~m}$ are shown and compared to the vertical profiles with a resolution of $75 \mathrm{~m}$, for the run at 13:31 UTC on 23 February 2016. Figure 9 illustrates the capability of HoloGondel to observe the variability of the cloud structure on the order of several meters. For example, the CDNC varies by a more than factor of 2 within an altitude interval of $75 \mathrm{~m}$ at 2450 and $2300 \mathrm{~m}$. The high-resolution profile also shows that over an altitude interval of about $50 \mathrm{~m}$ no cloud droplets where observed just below $2600 \mathrm{~m}$. These features are not visible if the data are averaged over an altitude interval of $75 \mathrm{~m}$ and provide a much more detailed picture of the microphysical parameters of the cloud. The high-resolution profile of the mean diameter on the right in Fig. 9 shows that its variation is small and the mean diameter steadily increases with increasing altitude except for the pocket of dry air at $2600 \mathrm{~m}$.

\subsection{Mixed-phase case}

During the first campaign at the Eggishorn in winter 2015, only the HOLIMO 3G instrument was mounted on the HoloGondel platform. Therefore the analysis of the mixed-phase case on 21 March 2015 is limited to the height profiles of the microphysical parameters and meteorological observations by the MeteoSwiss station at the Eggishorn.

The noise level of the holograms captured during the 2015 campaign was considerably higher due to mechanical instabilities in the optical setup of the HOLIMO $3 \mathrm{G}$ instrument.
As a consequence, the separation between cloud droplets and ice crystals was possible only for particles larger than $35 \mu \mathrm{m}$. Therefore, all particles smaller than $35 \mu \mathrm{m}$ are considered to be cloud droplets. As the ICNC is 2 to 3 orders of magnitude smaller than the CDNC, this has little effect on the results for the CDNC and mean diameter.

Figure 10 shows the height profiles for the number concentration, mean diameter and water content of cloud droplets and ice crystals. The height profiles of CDNC show a consistent trend during the morning: the number concentration decreases with decreasing altitude to a value less than $20 \mathrm{~cm}^{-3}$ below $2300 \mathrm{~m}$ before 11:00 UTC and below $2400 \mathrm{~m}$ after 11:00 UTC and the mean cloud droplet diameter profiles do not show a high temporal variability. There is a maximum of the mean diameter at an altitude of $2600 \mathrm{~m}$. Above the mean diameter decreases to $16 \mu \mathrm{m}$ and below it decreases to $13 \mu \mathrm{m}$ at $2300 \mathrm{~m}$. The decrease of CDNC at altitudes below $2500 \mathrm{~m}$ suggests either a nearly complete glaciated cloud or that cloud base is near the Fiescheralp. Both possibilities explain the rapid decrease of the mean cloud droplet diameter by the evaporation in air subsaturated with respect to liquid water.

The height profiles of the ICNC show a much higher temporal and vertical variability, varying from 0 to $75 \mathrm{~L}^{-1}$ between different runs and by a factor of 3 in the profile at 11:13 UTC. For the runs at 09:31, 09:53 and 11:31 UTC the profiles of mean ice crystal diameter and ice water content (IWC) slightly increase with decreasing altitude below $2800 \mathrm{~m}$. A growth of ice crystals at the expense of cloud droplets is expected in a mixed-phase cloud due to the Wegener-Bergeron-Findeisen process (Wegener, 1911; Bergeron, 1935; Findeisen, 1938). The vertical profiles have in common that the ice water content to total water content ratio (IWC / TWC) increases with decreasing altitude, suggesting a completely glaciated cloud. However, webcam pictures from the Fiescheralp suggest that cloud base was above the lower cable car station; thus probably a few ice crystals fell out and were observed with the HoloGondel instrument.

An interesting feature is the high variability of ICNC (Fig. 10). Possible mechanisms to explain the observed variability of ICNC can only be discussed briefly, because meteorological parameters were not measured. Very localized high ice nucleation rates cannot explain the observed ICNC of several tens per liter at the observed temperature of $-5^{\circ} \mathrm{C}$ because the average concentration of ice nucleating particles observed at the nearby Jungfraujoch did not exceed $7 \mathrm{stdL}^{-1}$ at $-32{ }^{\circ} \mathrm{C}$ (Boose et al., 2016). Ice crystals may also fall into the cloud from an ice cloud lying above, which was observed on satellite pictures. On 23 February 2016, there was no ice cloud observed above and in the same temperature range simply a liquid cloud was observed instead. Secondary ice multiplication processes can further enhance the ICNC in the observed cloud. An influence due to ground-based processes is not expected because the cable car is more than $100 \mathrm{~m}$ above the surface at $2700 \mathrm{~m}$, where the highest ICNC was observed. 


\section{March 2015}

Liquid
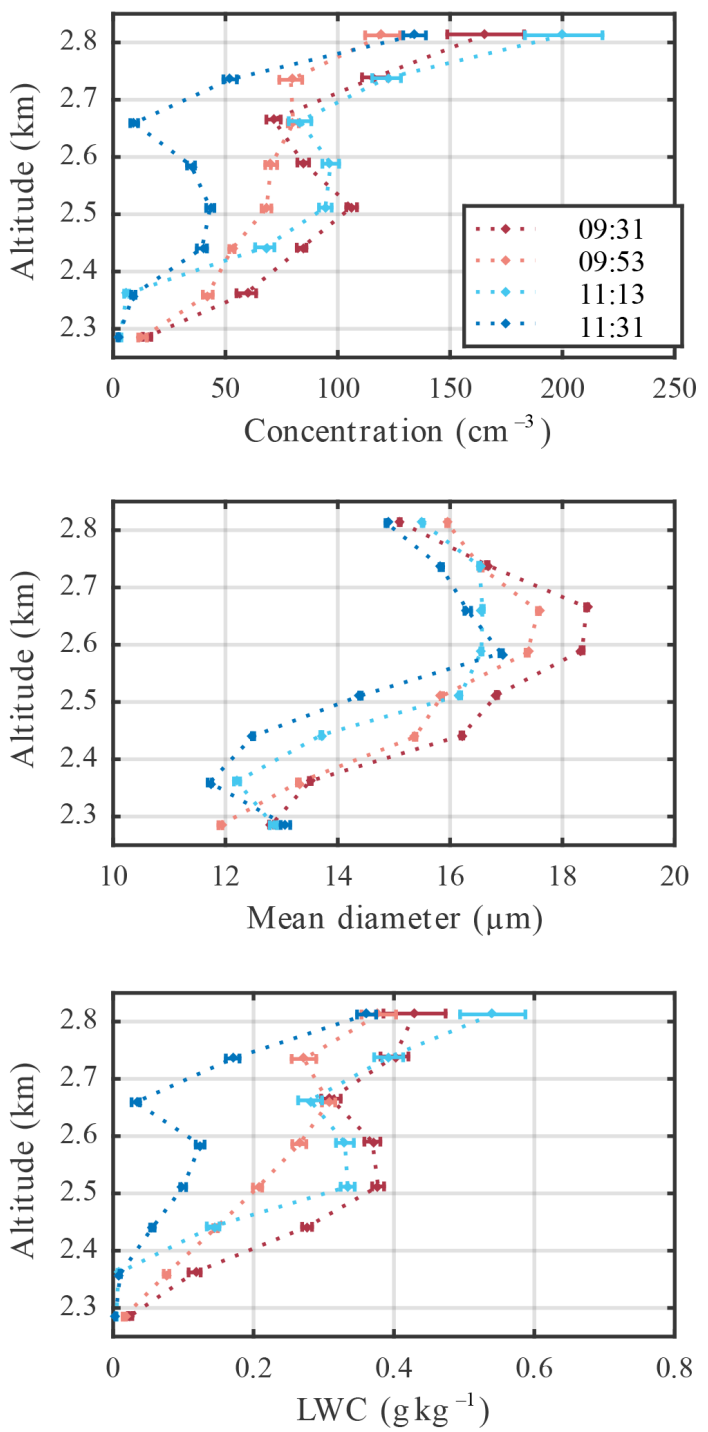

Ice
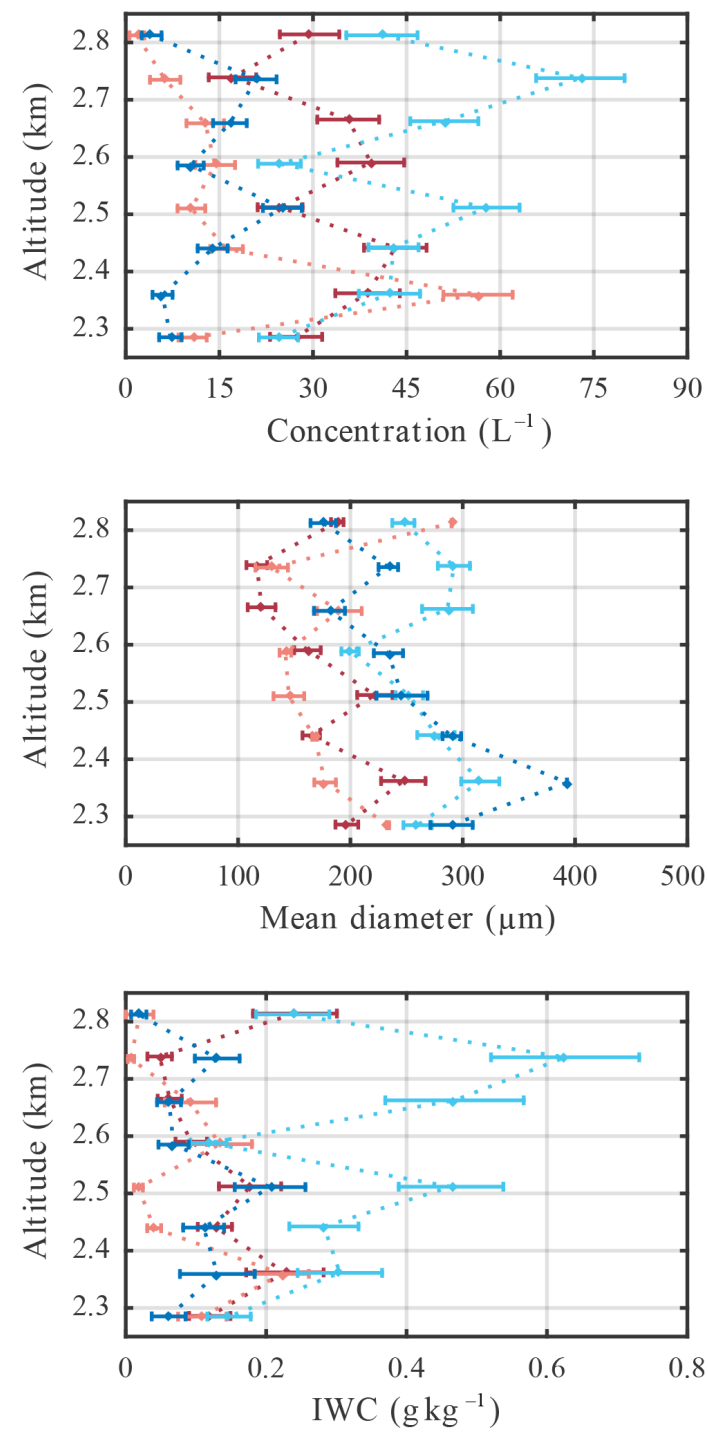

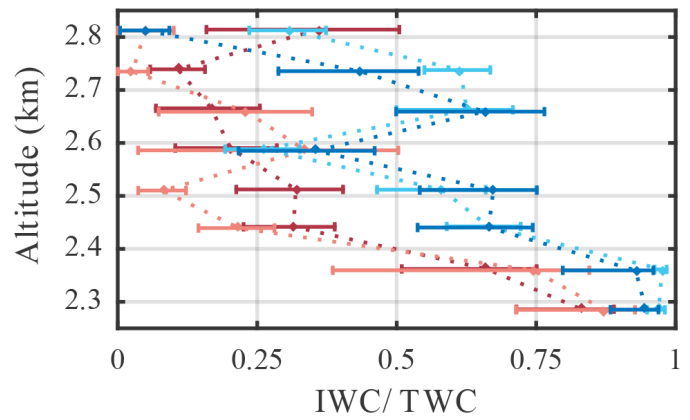

Figure 10. Height profiles of the cloud droplet and ice crystal number concentration, mean diameter and water content (LWC and IWC) and the ratio of the ice water content to total water content (IWC / TWC) on 21 March 2015. The data are averaged over an altitude interval of $75 \mathrm{~m}$. The error bars represent the standard error of the mean for the CDNC and the cloud droplet and ice crystals mean diameter. Due to the low ICNC the larger Poisson error is shown for the ICNC. For the LWC and the IWC the error was calculated using error propagation based on the error estimate for the particle concentration and mean diameter. For the ratio IWC / TWC the errors represent the minimum and maximum value based on the error for the LWC and IWC. 
A much lower ICNC was observed where the cable car was closer to the surface. The Hallet-Mossop process is a possible ice multiplication mechanism that can explain very localized spikes of high ICNC, which is active at $-5^{\circ} \mathrm{C}$ and can significantly increase the ICNC (Hallet and Mossop, 1974). Also the small $(<13 \mu \mathrm{m})$ and large $(>25 \mu \mathrm{m})$ liquid droplets required for the Hallet-Mossop process were observed on this day (Mossop, 1976, 1978).

It is important to mention that the cable car is above a ski slope during its ride and the production of artificial snow with snow canons could be a possible explanation for the high variability in the ICNC. Small variations in the wind speed and direction due to local turbulence could move the artificial snow to very different locations and may explain the high variability of the ICNC. Further investigation of the ice crystal habit from their 2-D images is also available with the HOLIMO $3 \mathrm{G}$ instrument and can help to solve this problem because ice crystals produced by surface-based processes or snow canons are expected to have a irregular shape. However, such an analysis was not performed for this case study.

A unique feature of holography is the information about the spatial distribution of the cloud particles within the sample volume (Fig. 11). The randomness of the spatial distribution of the cloud droplets has been tested using nearestneighbor analysis. The measured mean inter-particle distance $\langle r\rangle$ is compared to the theoretical mean inter-particle distance for a random distribution (Hertz, 1909):

$\left\langle r_{\text {random }}\right\rangle=0.554 \frac{1}{\sqrt[3]{n}}$,

where $n$ is the particle concentration in the volume. If the ratio

$R=\frac{\langle r\rangle}{\left\langle r_{\text {random }}\right\rangle}$

is equal to 1 , the particles are randomly distributed in the volume. The larger the deviation of the ratio $R$ from 1 to smaller values, the stronger are the particles clustered within in the observed volume.

The presented examples are from the run at 09:31 UTC. The spatial distribution on top of Fig. 11 represents a cloud at an altitude of $2600 \mathrm{~m}$ with a ICNC of $605 \mathrm{~L}^{-1}$ and a CDNC of $118 \mathrm{~cm}^{-3}$. For the cloud droplets, the ratio $R$ is equal to 1.033, whereas it is much smaller for the ice crystals and was calculated as $R=0.65$. This suggests that the cloud droplets are distributed randomly within the sample volume, whereas the ice crystals are clustered. This reflects the high variability of the ICNC compared to the CDNC discussed above. The spatial distribution on the bottom of Fig. 11 was taken at an altitude of $2300 \mathrm{~m}$ with smaller ice crystal $\left(<50 \mathrm{~cm}^{-3}\right)$ and cloud droplet $\left(<50 \mathrm{~cm}^{-3}\right)$ number concentrations. This is in the region of the cloud base and the cloud volume is strongly diluted and filamented possibly due to turbulent mixing with clear air as it was also observed in Beals et al. (2015). This observation is reflected in a small value of $R$ of 0.51 . Because only a single ice crystal was observed in this hologram the nearest-neighbor analysis was not possible for the ice crystals.

\section{Discussion and further improvements}

\subsection{Observation of meteorological parameters}

As described in Sect.2, wind measurements have to be corrected for movement of the cable car. In Fig. 7 the corrected wind speed and direction is compared to the MeteoSwiss wind measurements at the Eggishorn at 2893 ma.s.1. The largest discrepancy for the wind direction is at the highest altitude interval of the HoloGondel measurements. Because this measurement point is the closest to the MeteoSwiss station at the top of the Eggishorn the best agreement is expected. The discrepancy is probably due to the orography just below the top station. As the cable car descends into the valley, at the beginning it travels along a little canyon which strongly influences the wind direction and possibly explains the discrepancy. Although the wind speed and wind direction measurements compare quite well for lower altitudes, this has to be interpreted with caution. The measurements of MeteoSwiss above the ridge of the Eggishorn might be quite different as it is freer airstream than in the valley where the wind is closely bounded by orographic forces.

As the temperature profile of the temperature sensor shows a delayed response to the temperature change during a cable car ride, the reported ambient temperature in Fig. 7 was calculated from the virtual temperature $T_{\mathrm{v}}$ measured with the 3-D sonic anemometer using

$T=T_{\mathrm{v}} \frac{0.622(1+w)}{w+0.622}$,

with the water vapor mixing ratio $w$ in $\mathrm{kg} \mathrm{kg}^{-1}$ air. The corrected temperature in the highest altitude level is consistent with the MeteoSwiss data (Fig. 7). The difference in temperature between the altitude levels of 2850 and $2250 \mathrm{~m}$ is $3.5 \mathrm{~K}$ according to the corrected temperature data of the 3 $\mathrm{D}$ sonic anemometer. An iterative calculation of the temperature difference based on the saturated adiabatic lapse rate yields $4.2 \mathrm{~K}$. This is less than the saturated adiabatic lapse rate, suggesting that the air was absolutely stable stratified over this layer.

\subsection{Observation of microphysical parameters}

Laboratory measurements with the HOLIMO 3G instrument have shown its capability to resolve particles larger than $6.2 \mu \mathrm{m}$ (Fig. 4). With an increasing number of particles in the sample volume the noise level is expected to increase due to particle-particle scattering and reference wave distortion. Following the argumentation of Beals et al. (2015), the noise 


\section{9:31 on 21 March 2015}

(a) $2600 \mathrm{~m}$

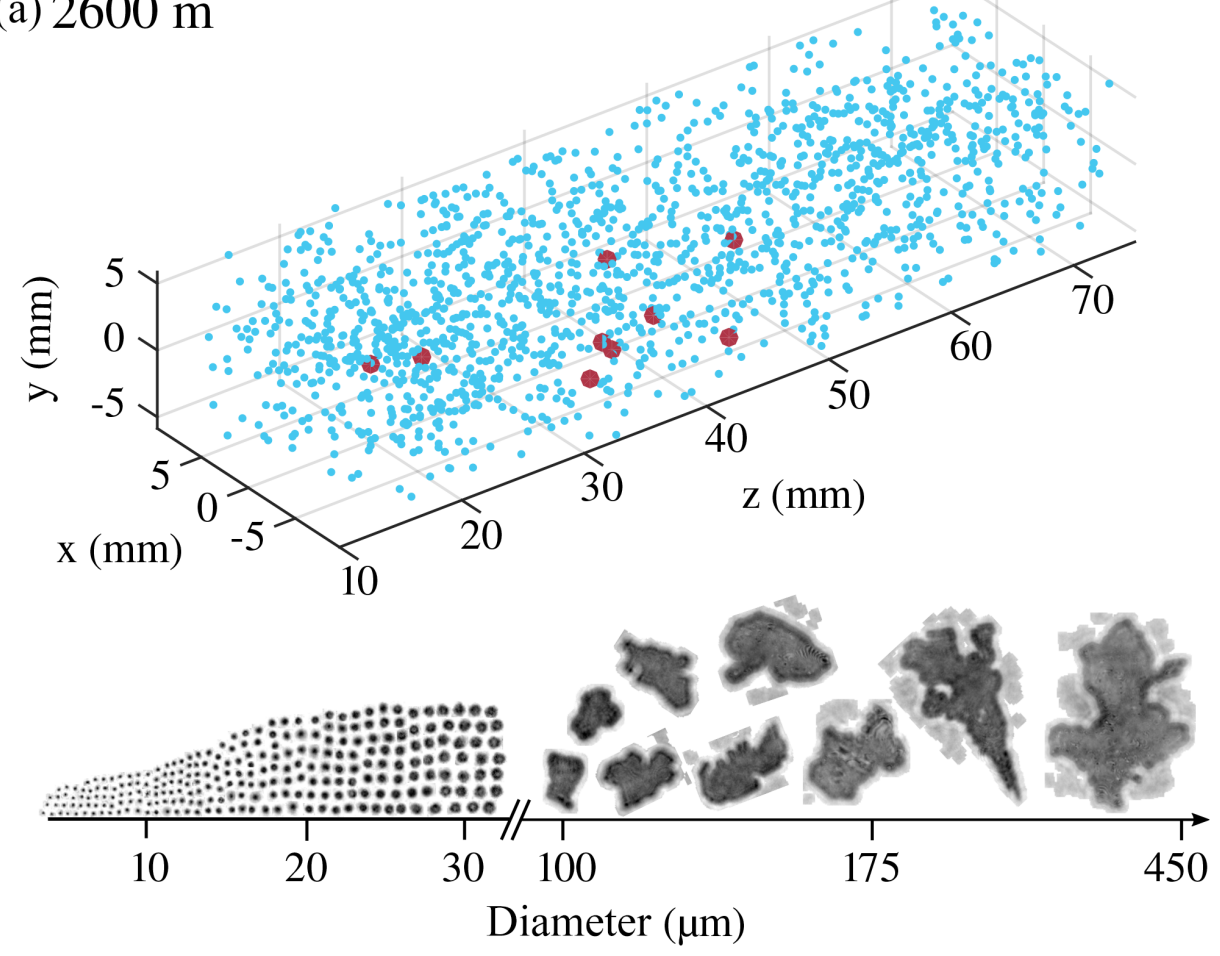

(b) $2300 \mathrm{~m}$
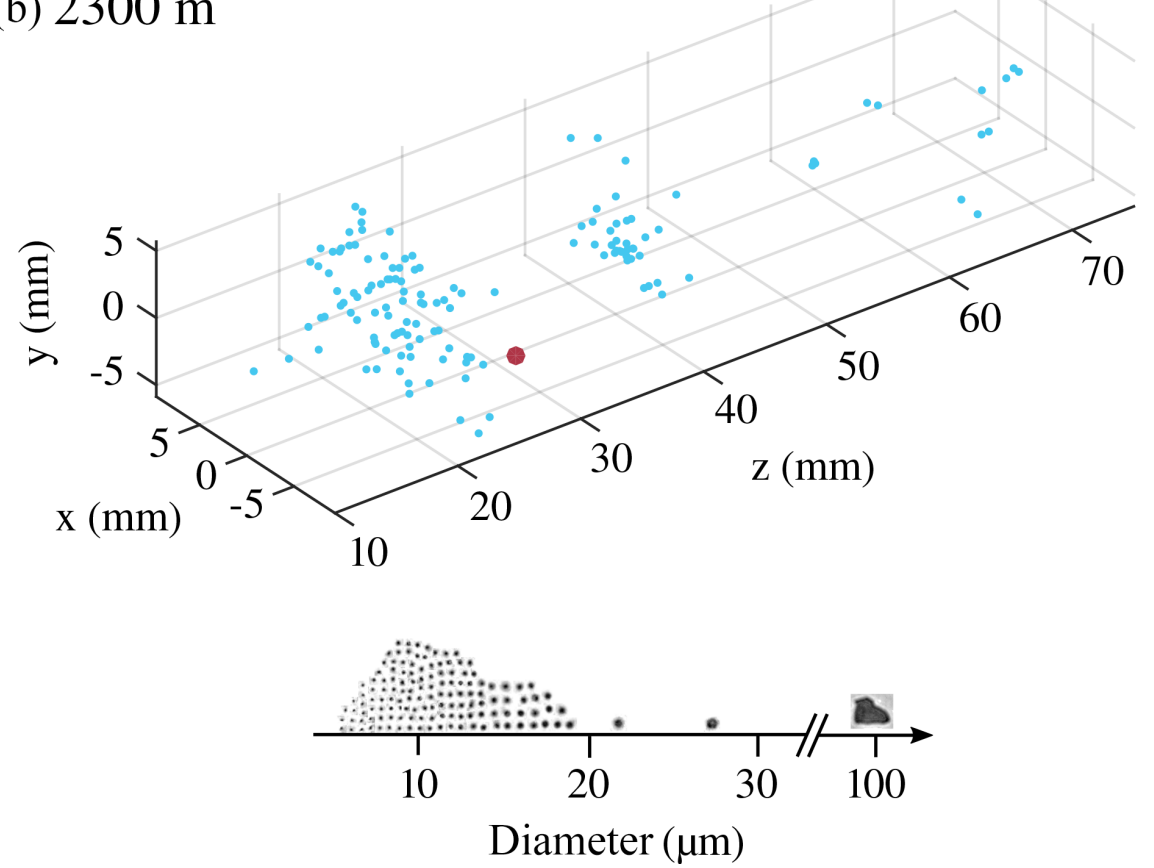

Figure 11. Spatial distribution of the liquid droplets (blue) and ice crystals (red) and examples of the 2-D images for two holograms captured at an altitude of $2600 \mathrm{~m}$ (a) and $2300 \mathrm{~m}$ (b) at 09:31 UTC on 21 March 2015. While the liquid droplets are distributed randomly in the sample volume at $2600 \mathrm{~m}$, the sample volume at $2300 \mathrm{~m}$ is strongly diluted and filamented. 
begins to noticeable increase if the projected area of all the particles in the sample volume exceeds $1 \%$ of the hologram area. Therefore, the particle number concentration for which a noticeable increase in noise is expected is given by

$n=\frac{4 f}{\pi d^{2} l}$,

where $f$ is the fraction of the hologram covered by particles, $d$ is the mean particle diameter and $l$ the length of the sample volume. For a mean droplet diameter of $10 \mu \mathrm{m}$ this increase is expected for a number concentration larger than $500 \mathrm{~cm}^{-3}$. Manual inspection by eye of cloud particles classified as cloud droplets by the HOLOSuite software has shown that HOLIMO $3 \mathrm{G}$ is capable of reliably observing cloud droplets starting at a size of $6.2 \mu \mathrm{m}$ for the run at 13:51 UTC on 23 February 2016, when the CDNC is close to $400 \mathrm{~cm}^{-3}$. This is in agreement with these theoretical considerations. Although liquid droplets of a size on the order of millimeters were not present in the example data presented, HOLIMO $3 \mathrm{G}$ is capable to detect particles in the size range of several micrometers to millimeters.

Phase partitioning was only possible for cloud particles larger than $35 \mu \mathrm{m}$ in 2015. This is a result of mechanical instabilities in the optical setup of the HOLIMO $3 \mathrm{G}$ instrument, which caused an increased noise level in holograms after background division and phase partitioning was significantly more difficult. After the field campaign in 2015 the optical setup was improved to a more rigid design, which reduced the noise level. As a result, a phase partitioning was possible for cloud particles starting at $25 \mu \mathrm{m}$ in 2016 .

As shown by the analysis of the spatial distribution (Fig. 11), holography allows investigation of spatial inhomogeneities of cloud droplets and ice crystals on a millimeter scale. A better understanding of the influence of turbulent mixing of a cloud with its environment on the spatial distribution of the cloud particles is of importance, because it influences cloud processes such as precipitation production or cloud dissolution. Upcoming analysis of the HoloGondel data will also focus on this topic especially when the cable car is entering or leaving a cloud during a run and measurements at the cloud edges are available.

The vertical resolution of the HoloGondel platform depends on the vertical velocity of the cable car. With a vertical distance of $650 \mathrm{~m}$ covered in $200 \mathrm{~s}$ the cable car at the Eggishorn has a mean vertical velocity of $3.25 \mathrm{~m} \mathrm{~s}^{-1}$. As 10 holograms are grouped together for counting statistic reasons, with a frame rate of $6 \mathrm{fps}$, this results in a maximum vertical resolution of $5 \mathrm{~m}$ (Fig. 9). In addition to the variability of the spatial distribution on the millimeter scale, the investigation of the variation of microphysical properties on a meter scale is possible. A sudden increase in the ICNC at this length scale for example can be evidence for a secondary ice multiplication process.

The temporal resolution of the HoloGondel platform is defined by the interval between two runs of the cable car, which is on the order of $10-15 \mathrm{~min}$ and the wind speed. In the case of the Eggishorn the cable car runs every 20 min (Figs. 7 and 10 ), and with a wind speed on the order of a few $\mathrm{m} \mathrm{s}^{-1}$ this results in a resolution of several kilometers.

In combination with vertical profiles of meteorological parameters, the dependency on microphysical properties of a cloud on temperature, wind speed or turbulence can be analyzed. The relationship between temperature and the observed ICNC is especially of interest for possible ice multiplication mechanisms. As the height above the surface is not constant during a run of the cable car, the dependency of the microphysical parameters on the distance above the surface is an additional point of interest for further studies. Lloyd et al. (2015) suggested surface-based process to explain the high ICNC observed at the Jungfraujoch, and measuring the dependency of ICNC on the height above the surface using HoloGondel may contribute to a better understanding of such processes. Finally, measurements on a cable car can easily be repeated over a time interval of several years.

\subsection{General issues of in situ cloud observations on a cable car}

The first two field campaigns at the Eggishorn revealed some unexpected difficulties for in situ cloud observation on a cable car. First, the battery of the HoloGondel platform has to be recharged at least every second night. To recharge the battery overnight, the cable car cabin with HoloGondel has to be in the lower station. This is not automatically the case and has to be taken care of by the operators of the cable car. During the 3-month period of the field campaign in 2016 the platform ran out of power twice, when the ski resort employees were occupied preparing the slopes over night and the cable car cabin with the HoloGondel platform was parked in the top station. Second, cable cars in ski resorts operate on a more irregular schedule during cloudy conditions because cloudy conditions attract fewer tourists. In such cases, the Eggishorn cable car was operated less than $50 \%$ of the regular schedule. However, since the HoloGondel platform is able to operate unattended for weeks - it is remotely accessible, the data are automatically transferred to the local server and the battery can easily be recharged by the cable car staff - a vast data set of vertical profiles is still achievable. In addition, there is usually the option to pay for extra runs of the cable car for a reasonable price on the order of 50 SFR. An alternative to a large cable car in a ski resort could be a small supply cable car, which can be operated on demand. The experience of field campaigns with HoloGondel at the Eggishorn made clear that the success of a field campaign depends on the employees of the cable car company. 


\section{Conclusions}

The HoloGondel platform has shown proof of concept that is can measure many vertical profiles of cloud microphysical parameters along with meteorological conditions unattended for days at a time. It has obtained example results from liquid and a mixed-phase clouds at the Eggishorn in the Swiss Alps. The main findings are as follows:

- HoloGondel is the first measurement platform to successfully observe vertical profiles of microphysical and meteorological cloud properties and their temporal evolution on a cable car during two field campaigns at the Eggishorn in the Swiss Alps.

- The findings of the liquid case on 23 February 2016 show cloud droplets larger than $6.5 \mu \mathrm{m}$ in a cloud with a number concentration as high as $380 \mathrm{~cm}^{-1}$ can reliably be observed with HOLIMO $3 \mathrm{G}$, the main component of the HoloGondel platform.

- For the mixed-phase case on 21 March 2015 separation between liquid droplets and ice crystals is possible for particles larger than $35 \mu \mathrm{m}$. An improvement of the design of HOLIMO $3 \mathrm{G}$ allows the separation for particles larger than $25 \mu \mathrm{m}$ for the campaign in 2016.

- HOLIMO 3G is capable of observing the spatial distribution of cloud particles in the sample volume on a millimeter scale as shown in Fig. 11. The observation of inhomogeneities of the spatial distribution of cloud particles allows investigation of the influence of entrainment and turbulent mixing on the development of a cloud.

- The HoloGondel platform is capable of observing the inhomogeneities and variability of the microphysical cloud parameters from a millimeter scale up to several kilometers. The spatial distribution of the cloud particles in the sample volume can be observed on a millimeter scale, whereas the vertical resolution is on the order of several meters. The temporal evolution is determined by the cable car schedule. In this case, it is on the order of 10-15 min, corresponding to a horizontal resolution of several kilometers between cloud penetrations.

- The high availability of measurements with the HoloGondel platform due to its low maintenance requirements can provide a large set of vertical profiles. In addition, the measurements can easily be repeated at the same location over several years forming a low-cloud climatology of the location.

- With its modular design the measurements with the HoloGondel platform can be easily adjusted to the needs of its users, limited only by weight and power restrictions. For example, observation of vertical profiles could be extended to aerosol measurements or additional cloud probes.
The HoloGondel platform has a unique approach for observing vertical profiles of microphysical and meteorological properties of mixed-phase clouds in complex alpine terrain, and has shown its feasibility during campaigns in 2015 and 2016 at the Eggishorn in the Swiss Alps. It overcomes the limitation of a single-point observation at mountain-top research stations and is capable of observing cloud structure and inhomogeneities from a millimeter scale up to several kilometers. With the high availability and repeatability of the measurements the HoloGondel platform offers the opportunity to improve the understanding of microphysical processes in clouds (e.g., precipitation initiation and ice multiplication).

\section{Data availability}

Pre-processsed data are avialable for download at https: //polybox.ethz.ch/index.php/s/mEexQI67pesStIa (Beck and Henneberger, 2017). The raw hologram data are available from the authors on request.

Competing interests. The authors declare that they have no conflict of interest.

Acknowledgements. We would like to thank Janina Stäudle for her assistance during the field campaign in winter 2015 and the following data analysis phase. The authors also thank the Luftseilbahnen Fiesch-Eggishorn AG staff for their excellent support during the field measurements. The meteorological measurements at the Eggishorn were provided by the Swiss Federal Office of Meteorology and Climatology MeteoSwiss. This project was supported by ETH Zurich under grant ETH-30 13-2.

Edited by: S. Malinowski

Reviewed by: D. Baumgardner and one anonymous referee

\section{References}

Amsler, P., Stetzer, O., Schnaiter, M., Hesse, E., Benz, S., Moehler, O., and Lohmann, U.: Ice crystal habits from cloud chamber studies obtained by in-line holographic microscopy related to depolarization measurements, Appl. Optics, 48, 5811-5822, doi:10.1364/AO.48.005811, 2009.

Baumann, K., Maurer, H., Rau, G., Piringer, M., Pechinger, U., Prévôt, A., Furger, M., Neininger, B., and Pellegrini, U.: The influence of south Foehn on the ozone distribution in the Alpine Rhine valley-results from the MAP field phase, Atmos. Environ., 35, 6379-6390, doi:10.1016/S1352-2310(01)00364-8, 2001.

Baumgardner, D., Brenguier, J., Bucholtz, A., Coe, H., DeMott, P., Garrett, T., Gayet, J., Hermann, M., Heymsfield, A., Korolev, A., Krämer, M., Petzold, A., Strapp, W., Pilewskie, P., Taylor, J., Twohy, C., Wendisch, M., Bachalo, W., and Chuang, P.: Airborne instruments to measure atmospheric aerosol particles, clouds and 
radiation: A cook's tour of mature and emerging technology, Atmos. Res., 102, 10-29, doi:10.1016/j.atmosres.2011.06.021, 2011.

Beals, M. J., Fugal, J. P., Shaw, R. A., Lu, J., Spuler, S. M., and Stith, J. L.: Holographic measurements of inhomogeneous cloud mixing at the centimeter scale, Science, 350, 87-90, doi:10.1126/science.aab0751, 2015.

Beck, A. and Henneberger, J.: Dataset of vertical profiles with HoloGondel at Eggishorn Switzerland (21.03.2015) and Hoher Sonblick, Austria (23.02.2016), Institute for Atmospheric and Climate Science, ETH Zurich, available at: https://polybox.ethz.ch/ index.php/s/mEexQI67pesStIa, last access: 4 February 2017.

Bergeron, T.: On the physics of clouds and precipitation, in: Proces Verbaux de l'Association de Météorologie, Int. Union of Geodesy and Geophys., Paris, France, 156-178, 1935.

Boose, Y., Kanji, Z. A., Kohn, M., Sierau, B., Zipori, A., Crawford, I., Lloyd, G., Bukowiecki, N., Herrmann, E., Kupiszewski, P., Steinbacher, M., and Lohmann, U.: Ice Nucleating Particle Measurements at $241 \mathrm{~K}$ during Winter Months at $3580 \mathrm{~m} \mathrm{MSL}$ in the Swiss Alps, J. Atmos. Sci., 73, 2203-2228, doi:10.1175/JAS-D15-0236.1, 2016

Borrmann, S. and Jaenicke, R.: Application Of Microholography for Ground-based In Situ Measurements in Stratus Cloud Layers: A Case Study, J. Atmos. Ocean. Tech., 10, 277-293, doi:10.1175/1520-0426(1993)010<0277:AOMFGB>2.0.CO;2, 1993.

Boucher, O., Randall, D., Artaxo, P., Bretherton, C., Feingold, G., Forster, P., Kerminen, V.-M., Kondo, Y., Liao, H., Lohmann, U., Rasch, P., Satheesh, S., Sherwood, S., Stevens, B., and Zhang, X.: Clouds and Aerosols, book Sect. 7, 571-658, Cambridge University Press, Cambridge, UK and New York, NY, USA, doi:10.1017/CBO9781107415324.016, 2013.

Conway, B., Caughey, S., Bentley, A., and Turton, J.: Ground-based and airborne holography of ice and water clouds, Atmos. Environ., 16, 1193-1207, doi:10.1016/0004-6981(82)90208-6, 1982.

Farrington, R. J., Connolly, P. J., Lloyd, G., Bower, K. N., Flynn, M. J., Gallagher, M. W., Field, P. R., Dearden, C., and Choularton, T. W.: Comparing model and measured ice crystal concentrations in orographic clouds during the INUPIAQ campaign, Atmos. Chem. Phys., 16, 4945-4966, doi:10.5194/acp-16-49452016, 2016.

Findeisen, W.: Kolloid-meteorologische Vorgänge bei Neiderschlagsbildung, Meteor. Z, 55, 121-133, 1938.

Flato, G., Marotzke, J., Abiodun, B., Braconnot, P., Chou, S., Collins, W., Cox, P., Driouech, F., Emori, S., Eyring, V., Forest, C., Gleckler, P., Guilyardi, E., Jakob, C., Kattsov, V., Reason, C., and Rummukainen, M.: Evaluation of Climate Models, in: Climate Change 2013: The Physical Science Basis. Contribution of Working Group I to the Fifth Assessment Report of the Intergovernmental Panel on Climate Change,741-866, Cambridge University Press, Cambridge, UK and New York, NY, USA, doi:10.1017/CBO9781107415324.020, 2013.

Fugal, J. P.: HOLOSuite, in preparation, 2017.

Fugal, J. P. and Shaw, R. A.: Cloud particle size distributions measured with an airborne digital in-line holographic instrument, Atmos. Meas. Tech., 2, 259-271, doi:10.5194/amt-2-259-2009, 2009.

Fugal, J. P., Schulz, T. J., and Shaw, R. A.: Practical methods for automated reconstruction and characterization of particles in digital in-line holograms, Meas. Sci. Technol., 20, 075501, doi:10.1088/0957-0233/20/7/075501, 2009.

Geerts, B., Pokharel, B., and Kristovich, D. A. R.: Blowing Snow as a Natural Glaciogenic Cloud Seeding Mechanism, Mon. Weather Rev., 143, 5017-5033, doi:10.1175/MWR-D-15-0241.1, 2015.

Gultepe, I. and Zhou, B.: FTS (Fog To Snow) Conversion Process During the SNOW-V10 Project, Pure Appl. Geophys., 169, 783791, doi:10.1007/s00024-011-0349-4, 2011.

Hallet, J. and Mossop, S.: Production of secondary ice particles during the riming process, Nature, 249, 26-28, doi:10.1038/249026a0, 1974.

Henneberger, J.: Mountain-top in situ observations of mixed-phase clouds with a digital holographic instrument, $\mathrm{PhD}$ thesis, ETH Zurich, Switzerland, 2013.

Henneberger, J., Fugal, J. P., Stetzer, O., and Lohmann, U.: HOLIMO II: a digital holographic instrument for ground-based in situ observations of microphysical properties of mixed-phase clouds, Atmos. Meas. Tech., 6, 2975-2987, doi:10.5194/amt-62975-2013, 2013.

Hertz, P.: Ueber den gegenseitigen durchschnittlichen Abstand von Punkten, die mit bekannter mittlerer Dichte im Raume angeordnet sind, Math. Ann., 67, 387-398, doi:10.1007/BF01450410, 1909.

Heymsfield, A. and Willis, P.: Cloud Conditions Favoring Secondary Ice Particle Production in Tropical Maritime Convection, J. Atmos. Sci., 71, 4500-4526, doi:10.1175/JAS-D-14-0093.1, 2014.

Joe, P., Scott, B., Doyle, C., Isaac, G., Gultepe, I., Forsyth, D., Cober, S., Campos, E., Heckman, I., Donaldson, N., Hudak, D., Rasmussen, R., Kucera, P., Stewart, R., Thériault, J. M., Fisico, T., Rasmussen, K. L., Carmichael, H., Laplante, A., Bailey, M., and Boudala, F.: The Monitoring Network of the Vancouver 2010 Olympics, Pure Appl. Geophys., 171, 25-58, doi:10.1007/s00024-012-0588-z, 2012.

Korolev, A. V., Emery, E. F., Strapp, J. W., Cober, S. G., Isaac, G. A., Wasey, M., and Marcotte, D.: Small Ice Particles in Tropospheric Clouds: Fact or Artifact? Airborne Icing Instrumentation Evaluation Experiment, B. Am. Meteorol. Soc., 92, 967973, doi:10.1175/2010BAMS3141.1, 2011.

Korolev, A. V., Emery, E. F., Strapp, J. W., Cober, S. G., and Isaac, G. A.: Quantification of the Effects of Shattering on Airborne Ice Particle Measurements, J. Atmos. Ocean. Tech., 30, 2527-2553, doi:10.1175/JTECH-D-13-00115.1, 2013.

Kozikowska, A., Haman, K., and Supronowicz, J.: Preliminary results of an investigation of the spatial distribution of fog droplets by a holographic method, Q. J. Roy. Meteor. Soc., 110, 65-73, doi:10.1002/qj.49711046306, 1984.

Lance, S., Brock, C. A., Rogers, D., and Gordon, J. A.: Water droplet calibration of the Cloud Droplet Probe (CDP) and inflight performance in liquid, ice and mixed-phase clouds during ARCPAC, Atmos. Meas. Tech., 3, 1683-1706, doi:10.5194/amt3-1683-2010, 2010.

Lawson, R. P., Stamnes, K., Stamnes, J., Zmarzly, P., Koskuliks, J., Roden, C., Mo, Q., Carrithers, M., and Bland, G. L.: Deployment of a Tethered-Balloon System for Microphysics and Radiative Measurements in Mixed-Phase Clouds at $\mathrm{Ny}$ Ålesund and South Pole, J. Atmos. Ocean. Tech., 28, 656-670, doi:10.1175/2010JTECHA1439.1, 2011. 
Lawson, R. P., Woods, S., and Morrison, H.: The Microphysics of Ice and Precipitation Development in Tropical Cumulus Clouds, J. Atmos. Sci., 72, 2429-2445, doi:10.1175/JAS-D-14-0274.1, 2015.

Lloyd, G., Choularton, T. W., Bower, K. N., Gallagher, M. W., Connolly, P. J., Flynn, M., Farrington, R., Crosier, J., Schlenczek, O., Fugal, J., and Henneberger, J.: The origins of ice crystals measured in mixed-phase clouds at the high-alpine site Jungfraujoch, Atmos. Chem. Phys., 15, 12953-12969, doi:10.5194/acp15-12953-2015, 2015.

Lohmann, U., Lüönd, F., and Mahrt, F.: An Introduction to clouds: from the microscale to the climate, Cambridge University Press, Cambridge, UK, 2016.

Lu, J., Fugal, J. P., Nordsiek, H., Saw, E. W., Shaw, R. A., and Yang, W.: Lagrangian particle tracking in three dimensions via singlecamera in-line digital holography, New J. Phys., 10, 125013, doi:10.1088/1367-2630/10/12/125013, 2008.

McFarlane, S. A. and Grabowski, W. W.: Optical properties of shallow tropical cumuli derived from ARM groundbased remote sensing, Geophy. Res. Lett., 34, 206808, doi:10.1029/2006GL028767, 2007.

Morrison, H., de Boer, G., Feingold, G., Harrington, J., Shupe, M. D., and Sulia, K.: Resilience of persistent Arctic mixed-phase clouds, Nat. Geosci., 5, 11-17, doi:10.1038/ngeo1332, 2012.

Mossop, S. C.: Production of secondary ice particles during the growth of graupel by riming, Q. J. Roy. Meteor. Soc., 102, 45-57, doi:10.1002/qj.49710243104, 1976.

Mossop, S. C.: The influence of drop size distribution on the production of secondary ice particles during graupel growth, Q. J. Roy. Meteor. Soc., 104, 323-330, doi:10.1002/qj.49710444007, 1978.

Piringer, M., Baumann, K., Pechinger, U., and Vogt, S.: Meteorological and ozone sounding experience during a strong foehn event a MAP case study, Meteorol. Z., 10, 445-455, doi:10.1127/0941-2948/2001/0010-0445, 2001.

Raupach, S. M. F., Vössing, H. J., Curtius, J., and Borrmann, S.: Digital crossed-beam holography for in situ imaging of atmospheric ice particles, J. Opt. A-Pure Appl. Op., 8, 796-806, doi:10.1088/1464-4258/8/9/014, 2006.

Reiter, R.: Upward flux of $\mathrm{RaB}$ and $\mathrm{RaC}$ in the planetary boundary layer as controlled by atmospheric microstructure, Pure Appl. Geophys., 72, 247-258, doi:10.1007/BF00875708, 1967.

Reiter, R. and Carnuth, W.: Comparing lidar reflectivity profiles against measured profiles of vertical aerosol distribution between 1 and $3 \mathrm{~km}$ a.s.1., Arch. Meteor. Geophy. A, 24, 69-92, doi:10.1007/BF02247559, 1975.

Rogers, D. C. and Vali, G.: Ice Crystal Production by Mountain Surfaces, J. Clim. Appl. Meteorol., 26, 1152-1168, doi:10.1175/1520-0450(1987)026<1152:ICPBMS>2.0.CO;2, 1987.

Schumann, U., Fahey, D. W., Wendisch, M., and Brenguier, J.L.: Introduction to Airborne Measurements of the Earth Atmosphere and Surface, 1-5, Wiley-VCH Verlag GmbH \& Co. KGaA, doi:10.1002/9783527653218.ch1, 2013.
Shupe, M. D., Daniel, J. S., de Boer, G., Eloranta, E. W., Kollias, P., Luke, E. P., Long, C. N., Turner, D. D., and Verlinde, J.: A Focus On Mixed-Phase Clouds, B. Am. Meteorol. Soc., 89, 1549-1562, doi:10.1175/2008BAMS2378.1, 2008.

Siebert, H., Lehmann, K., Wendisch, M., Franke, H., Maser, R., Schell, D., Saw, E. W., and Shaw, R. A.: Probing Finescale Dynamics and Microphysics of Clouds with HelicopterBorne Measurements, B. Am. Meteorol. Soc., 87, 1727-1738, doi:10.1175/BAMS-87-12-1727, 2006.

Sikand, M., Koskulics, J., Stamnes, K., Hamre, B., Stamnes, J. J., and Lawson, R. P.: Estimation of Mixed-Phase Cloud Optical Depth and Position Using In Situ Radiation and Cloud Microphysical Measurements Obtained from a Tethered-Balloon Platform, J. Atmos. Sci., 70, 317-329, doi:10.1175/JAS-D-12-063.1, 2013.

Spuler, S. M. and Fugal, J.: Design of an in-line, digital holographic imaging system for airborne measurement of clouds, Appl. Optics, 50, 1405-1412, doi:10.1364/AO.50.001405, 2011.

Sun, Z. and Shine, K. P.: Studies of the radiative properties of ice and mixed-phase clouds, Q. J. Roy. Meteor. Soc., 120, 111-137, doi:10.1002/qj.49712051508, 1994.

Thompson, B. J.: A New Method of Measuring Particle Size by Diffraction Techniques, Jpn. J. Appl. Phys., 3, 302-307, doi:10.7567/JJAPS.1S1.302, 1964.

Uchiyama, A., Yamazaki, A., Shiobara, M., and Kobayashi, H.: Case study on microphysical properties of boundary layer mixedphase cloud observed at Ny-Ålesund, Svalbard: Observed cloud microphysics and calculated optical properties on 9 June 2011, Polar Science, 8, 57-72, doi:10.1016/j.polar.2013.11.001, 2014.

Verlinde, J., Harrington, J. Y., Yannuzzi, V. T., Avramov, A., Greenberg, S., Richardson, S. J., Bahrmann, C. P., McFarquhar, G. M., Zhang, G., Johnson, N., Poellot, M. R., Mather, J. H., Turner, D. D., Eloranta, E. W., Tobin, D. C., Holz, R., Zak, B. D., Ivey, M. D., Prenni, A. J., DeMott, P. J., Daniel, J. S., Kok, G. L., Sassen, K., Spangenberg, D., Minnis, P., Tooman, T. P., Shupe, M., Heymsfield, A. J., and Schofield, R.: The Mixed-Phase Arctic Cloud Experiment, B. Am. Meteorol. Soc., 88, 205-221, doi:10.1175/BAMS-88-2-205, 2007.

Vidaurre, G. and Hallett, J.: Ice and water content of stratiform mixed-phase cloud, Q. J. Roy. Meteor. Soc., 135, 1292-1306, doi:10.1002/qj.440, 2009.

Vochezer, P., Järvinen, E., Wagner, R., Kupiszewski, P., Leisner, T., and Schnaiter, M.: In situ characterization of mixed phase clouds using the Small Ice Detector and the Particle Phase Discriminator, Atmos. Meas. Tech., 9, 159-177, doi:10.5194/amt-9-1592016, 2016.

Wegener, A.: Thermodynamik der Atmosphäre, Barth, Leipzig, Germany, 1911.

Zhang, D., Wang, Z., and Liu, D.: A global view of midlevel liquidlayer topped stratiform cloud distribution and phase partition from CALIPSO and CloudSat measurements, J. Geophys. ResAtmos., 115, D00H13, doi:10.1029/2009JD012143, 2010. 